\title{
Development and Characterization of Electrospun Fiber-Based Poly(ethylene-co-vinyl Alcohol) Films of Application Interest as High-Gas-Barrier Interlayers in Food Packaging
}

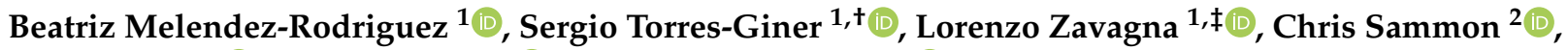 \\ Luis Cabedo $^{3}\left(\mathbb{D}\right.$, Cristina Prieto ${ }^{1}(\mathbb{D})$ and Jose M. Lagaron ${ }^{1, *(\mathbb{D})}$
}

1 Novel Materials and Nanotechnology Group, Institute of Agrochemistry and Food Technology (IATA), Spanish Council for Scientific Research (CSIC), Calle Catedrático Agustín Escardino Benllonch 7, 46980 Valencia, Spain; beatriz.melendez@iata.csic.es (B.M.-R.); storresginer@upv.es (S.T.-G.); lorenzo@zavagna.it (L.Z.); cprieto@iata.csic.es (C.P.)

2 Materials and Engineering Research Institute, Sheffield Hallam University, Sheffield S1 1WB, UK; c.sammon@shu.ac.uk

3 Polymers and Advanced Materials Group (PIMA), School of Technology and Experimental Sciences, Universitat Jaume I (UJI), Avenida de Vicent Sos Baynat s/n, 12071 Castellón, Spain; lcabedo@uji.es

* Correspondence: lagaron@iata.csic.es; Tel.: +34-963-900-022

+ This author is currently with the Research Institute of Food Engineering for Development (IIAD), Universitat Politècnica de València (UPV), Camino de Vera s/n, 46022 Valencia, Spain.

Citation: Melendez-Rodriguez, B. Torres-Giner, S.; Zavagna, L.; Sammon, C.; Cabedo, L.; Prieto, C.; Lagaron, J.M. Development and Characterization of Electrospun Fiber-Based Poly(ethylene-co-vinyl Alcohol) Films of Application Interest as High-Gas-Barrier Interlayers in Food Packaging. Polymers 2021, 13, 2061. https://doi.org/10.3390/ polym13132061

Academic Editor: Alexey Iordanski

Received: 14 May 2021

Accepted: 21 June 2021

Published: 23 June 2021

Publisher's Note: MDPI stays neutral with regard to jurisdictional claims in published maps and institutional affiliations.

Copyright: (c) 2021 by the authors Licensee MDPI, Basel, Switzerland. This article is an open access article distributed under the terms and conditions of the Creative Commons Attribution (CC BY) license (https:// creativecommons.org/licenses/by/ $4.0 /)$ $\ddagger \quad$ This author is on leave from the Interuniversity National Consortium of Materials Science and Technology (INSTM), 50121 Florence, Italy.

Abstract: In the present study, poly(ethylene-co-vinyl alcohol) with $44 \mathrm{~mol} \%$ ethylene content $\left(\mathrm{EVOH}_{44}\right)$ was managed to be processed, for the first time, by electrospinning assisted by the coaxial technology of solvent jacket. In addition to this, different suspensions of cellulose nanocrystals (CNCs), with contents ranging from 0.1 to $1.0 \mathrm{wt} \%$, were also electrospun to obtain hybrid bio/non-bio nanocomposites. The resultant fiber mats were thereafter optimally annealed to promote interfiber coalescence at $145{ }^{\circ} \mathrm{C}$, below the $\mathrm{EVOH}_{44}$ melting point, leading to continuous transparent fiber-based films. The morphological analysis revealed the successful distribution of CNCs into $\mathrm{EVOH}_{44}$ up to contents of $0.5 \mathrm{wt} \%$. The incorporation of CNCs into the ethylene-vinyl alcohol copolymer caused a decrease in the crystallization and melting temperatures $\left(\mathrm{T}_{\mathrm{C}}\right.$ and $\left.\mathrm{T}_{\mathrm{m}}\right)$ of about 12 and $7{ }^{\circ} \mathrm{C}$, respectively, and also crystallinity. However, the incorporation of $\mathrm{CNCs}$ led to enhanced thermal stability of the copolymer matrix for a nanofiller content of $1.0 \mathrm{wt} \%$. Furthermore, the incorporation of 0.1 and $0.5 \mathrm{wt} \% \mathrm{CNC}$ s produced increases in the tensile modulus (E) of ca. $38 \%$ and $28 \%$, respectively, but also yielded a reduction in the elongation at break and toughness. The oxygen barrier of the hybrid nanocomposite fiber-based films decreased with increasing the CNCs content, but they were seen to remain high barrier, especially in the low relative humidity $(\mathrm{RH})$ regime, i.e., at $20 \% \mathrm{RH}$, showing permeability values lower than $0.6 \times 10^{-20} \mathrm{~m}^{3} \cdot \mathrm{m} \cdot \mathrm{m}^{-2} \cdot \mathrm{Pa}^{-1} \cdot \mathrm{s}^{-1}$. In general terms, an optimal balance in physical properties was found for the hybrid copolymer composite with a CNC loading of $0.1 \mathrm{wt} \%$. On the overall, the present study demonstrates the potential of annealed electrospun fiber-based high-barrier polymers, with or without CNCs, to develop novel barrier interlayers to be used as food packaging constituents.

Keywords: EVOH; cellulose nanocrystals; electrospinning; high barrier; food packaging

\section{Introduction}

Polymers have been replacing the materials traditionally used in packaging, such as metal, glass, or cardboard, because they are more flexible, lighter, and habitually more cost-effective [1]. However, polymer-based materials present certain disadvantages, such as higher permeability and sorption to gases like oxygen or carbon dioxide, moisture, 
and organic vapors. In addition, polymer films must also present transparency, high mechanical and chemical resistance as well as be food contact approved [2]. In this sense, the thermoplastic poly(ethylene-co-vinyl alcohol) (EVOH), also habitually termed ethylene vinyl alcohol copolymers, are one of the most used polymer materials in highbarrier packaging films. EVOH is produced by the hydrolysis of ethylene vinyl acetate copolymer (EVA), where the acetate groups are transformed in alcohol ones [3]. In food packaging, EVOH is habitually placed in the form of thin inner layers, typically well below $10 \mu \mathrm{m}$, being protected from moisture by external layers of such as polypropylene (PP), polyethylene terephthalate (PET) or low- and high-density polyethylene (LDPE and HDPE) in multilayer structures [4]. The characteristics that make it suitable for this purpose are its flexibility, transparency, thermal resistance, and high-oxygen-barrier property based on its high degree of crystallinity [5-7]. Moreover, EVOH films are highly transparent and hydrophilic, yet water-insoluble, and can be recycled in the polyolefin regrinding process with existing infrastructure [8]. Interestingly, the EVOH copolymers, including that with $44 \mathrm{~mol} \%$ ethylene content $\left(\mathrm{EVOH}_{44}\right)$, with high vinyl-alcohol contents, have been proven to be able to degrade under certain environmental conditions and biological media [9-12].

The ethylene molar fraction present in the copolymer highly changes the properties of EVOH due to alterations in its molecular structure. In particular, when the ethylene content is below $42 \mathrm{~mol} \%, \mathrm{EVOH}$ crystals are small, dense, and in monoclinic crystal structure. However, for ethylene contents from 42 to $80 \mathrm{~mol} \%$, its crystals are larger, less dense, and in hexagonal crystal structure [13]. The crystallinity structure highly affects both the gas barrier and melting temperature $\left(\mathrm{T}_{\mathrm{m}}\right)$, being higher for the materials with lower ethylene contents, but these copolymers are also highly plasticized by moisture [14]. For instance, when the ethylene content in $\mathrm{EVOH}$ is increased, the oxygen transmission rate (OTR) increases exponentially [15].

In addition to multilayers, nanofillers can be employed with $\mathrm{EVOH}$ in order to improve their thermal, mechanical, and barrier properties. In this respect, cellulose nanomaterials have been regarded as great candidates since they are low-cost, renewable, and environmentally friendly [16]. Indeed, cellulose is the most abundant natural polysaccharide with an annual production around 75-100 billion tons [17], and it is formed of repeating rings of $\beta$-1,4-linked D-glucopyranose united by strong intermolecular hydrogen bonds [18]. It is part of the structure of plants and algae, bacteria and fungi, and tunicate [19]. There are two main types of nanocelluloses, that is, mechanically sheared cellulose nanofibers (CNFs), also termed micro-fibrillated cellulose (MFC), with amorphous and crystalline parts, and hydrolytically extracted cellulose nanocrystals (CNCs) made of high-purity single crystals [20,21]. Another type of nanocellulose derives from bacterial cellulose (BC), whose morphology can be engineered by controlling the biosynthesis pathway [22]. Among nanocellulose materials, $\mathrm{CNC}$ is one of the most promising nanofillers to reinforce the mechanical and barrier properties of polymers due to their high crystallinity and strong network [23]. Several studies have already reported the reinforcement achieved when CNCs have been incorporated to a polymer matrix [24,25]. For instance, a polyvinyl alcohol (PVA)/chitosan nanocomposite film reinforced with CNCs, prepared using the solvent casting and evaporation technique, showed an increase of $130 \%$ in tensile strength [26]. In other study, a PET/CNCs film improved the water vapor transmission rate of PET from 37 to $10 \mathrm{~g} \cdot \mathrm{m}^{-2} \cdot$ day $^{-1}$ [27]. Furthermore, CNCs can serve as vehicles to develop active polymeric materials with, for instance, antimicrobial and antioxidant properties [28,29], ultraviolet light (UV) blocking [30], heavy metal absorbers [31], etc. Nanohybrids made from CNCs/metal nanoparticles (MNPs) have also gained interest due to their combined properties. Thus, oxygen scavenging nanocomposites were obtained with the incorporation of CNCs and palladium nanoparticles (PdNPs) into EVOH films [32]. CNCs acted as a support for the dispersion of the PdNPs in the polymer matrix, while the PdNPs acted as oxygen scavengers. Similarly, alginate bionanocomposite films with CNCs and silver nanoparticles (AgNPs) showed improved water and UV barrier of interest in food packaging [33]. 
However, there are some drawbacks to consider when $\mathrm{CNC}$ was used as blending element to reinforce or make more sustainable polymer matrices. In particular, CNCs tend to form aggregates in the polymer matrix causing an overall reduction of the physical properties of the nanocomposites. This agglomeration is produced by the hydrophilic nature of cellulose, which is prone to form strong intermolecular hydrogen bonds and, in the case of CNCs, this effect is increased due to its large surface area and high surface energy [34]. As a result, CNCs are prepared in the form of water suspensions, which however tend to re-agglomerate during the drying process. For instance, in spray drying, CNCs agglomeration is caused by capillary, hydrogen-bonding, and van der Waals forces. Alternatively, ice crystal growth plays a key role in CNC agglomeration during freeze drying. Agglomeration of CNCs unsuccessfully affects the mechanical and barrier advantages of the polymer nanocomposites. The minimum degree of the $\mathrm{CNC}$ dispersion is also so-called percolation threshold, where a three-dimensional network is obtained from a specific concentration of nanoparticles [35]. This percolation threshold depends on the aspect ratio and the orientation and distribution of the CNCs [36]. Moreover, the method used to form the nanocomposites also influences on the dispersion of CNCs [37].

Therefore, novel strategies have been explored to reduce the aggregations of CNCs prior or during their incorporation into the polymer matrices. For example, unlike spray and freeze drying, less agglomeration was reported to occur in the spray-freeze drying technique, in which the dispersed state of CNCs in water can be "frozen" in [38]. Moreover, the use of mechanical energy can be applied to separate the nanoparticles, such as high shear mixing or ultrasonication, as well as the change in the surface energy of the particles by surfactants/compatibilizers [39,40]. Traditional melt-processing methods such as extrusion [41], compounding [42], and injection molding [43] have also been used to incorporate CNCs into polymer matrices. However, the use of high temperatures during these processes could also cause the degradation of the CNCs [44]. In addition, it has been found that these methods produce more particle aggregation and mechanical degradation due to the high shear attained during processing [45]. Thus, solution processing methods such as solution casting [46], solution precipitation [47], or electrospinning [48-52] have been explored. In some cases, different methods can be combined to attain higher $\mathrm{CNC}$ dispersion [53].

In this regard, electrospinning is a promising technology for dispersing CNCs in polymer matrices since it works with polymer solutions and can incorporate the fillers into submicron fibers [54,55]. Moreover, the electrospun mats can be, thereafter, post-treated at temperatures below the $T_{m}$ of the polymer, forming fiber-based continuous films with eliminated porosity. These materials are also called "biopapers" when made of biopolymers [56,57] due to their biofiber-based morphology and improved properties compared to traditional cellulosic papers. Thus, these materials can be produced after using minimal thermal exposure and they show good optical as well as mechanical and barrier properties, potentially offering high value in food packaging applications [58]. Moreover, electrospinning is suitable for the incorporation of nanofillers and/or functional additives within the polymer fibers, for instance volatile or thermolabile substances such as essential oils [59,60]. In addition, the resultant electrospun layers can be used as coatings or interlayers [59] to improve the mechanical and barrier properties of multilayer systems. A few previous studies have reported the electrospinning of polymers containing CNCs. For example, Redondo et al. [61] incorporated CNCs into polyurethane (PU) fibers and reported an improvement in the mechanical properties of the nanocomposite fiber mats. In another work, PVA mats prepared by electrospinning were mixed with CNC solutions to form aerogels that were subsequently hot-pressed to form nanocomposites. Authors showed good CNC dispersion with increased mechanical properties [62]. In the case of the ethylene vinyl alcohol copolymer with $27 \mathrm{~mol} \%$ ethylene content $\left(\mathrm{EVOH}_{27}\right)$, Martinez et al. [63] developed fibers reinforced with bacterial cellulose nanowhiskers (BCNWs) by electrospinning with a more uniform morphology than the neat $\mathrm{EVOH}_{27}$ fibers. However, none 
of the previous studies reported the production of post-processed continuous films or their properties.

The current study was aimed at obtaining for the first time (i) a new high-barrier electrospun material made of $\mathrm{EVOH}_{44}$ copolymer and (ii) hybrid nanocomposites made of two high-barrier materials, one of which, incorporating CNCs in powder form, can impart a stiffer and more sustainable bio-based character to $\mathrm{EVOH}_{44}$. The reason to select $\mathrm{EVOH}_{44}$ within the EVOH family is that this polymer shows lower $\mathrm{T}_{\mathrm{m}}$ and, hence, lower postprocessing temperatures than other EVOH family copolymers with higher vinyl-alcohol contents by which it could be more compatible with the processing temperatures of more conventional or biodegradable polymers to form multilayers. However, the processability of this copolymer by the electrohydrodynamic technique used was proven to be very difficult, so the study had to resource to the coaxial technology of solvent jacket. The study also characterized physical properties such as optical, thermal, mechanical, and barrier properties, relevant for multilayer food packaging applications of the annealed electrospun continuous films produced.

\section{Materials and Methods}

\subsection{Materials}

The ethylene vinyl alcohol copolymer grade (Soarnol AT4403) containing $44 \mathrm{~mol} \%$ of ethylene, that is, $\mathrm{EVOH}_{44}$, was supplied in pellets by The Nippon Synthetic Chemical Industry Co., Ltd. (NIPPON GOHSEI, Osaka, Japan). It has a density of $1.14 \mathrm{~g} / \mathrm{m}^{3}$, melt flow rate (MFR) of $3.5 \mathrm{~g} / 10 \mathrm{~min}\left(210^{\circ} \mathrm{C}, 2.16 \mathrm{~kg}\right)$, and a volatile content $<0.3 \%$. The CNCs were provided by CelluForce NCC ${ }^{\circledR}$ (Montreal, QC, Canada). It is a 100\% cellulose sulphate sodium salt, which was obtained from wood pulp. The nanofiller was supplied as a spray-dried solid white powder with a bulk density of $0.7 \mathrm{~g} / \mathrm{cm}^{3}$. 2-propanol $(99.5 \%$, for analysis) was purchased by ACROS ORGANICS (Thermo Fisher Scientific, Waltham, MA, USA).

\subsection{Preparation of Solutions}

The $\mathrm{EVOH}_{44}$ solutions for electrospinning were prepared in concentration of $6 \%$ $(\mathrm{wt} / \mathrm{vol})$ in a $70 / 30 \mathrm{vol} / \mathrm{vol}$ mixture of 2-propanol/water. The mixture was continuously stirred and heated in a thermal bath at approximately $80-90{ }^{\circ} \mathrm{C}$ on an AGIMATIC-N magnetic stirrer from JP Selecta (Barcelona, Spain). Complete dissolution of the polymer was achieved after around 2-3 h and the solutions were cooled down at room temperature prior to electrospinning. Since precipitation of the polymer always occurs after $3-4 \mathrm{~h}$ at room temperature [64], the precipitated mixture was heated again to $60^{\circ} \mathrm{C}$ for $30-45 \mathrm{~min}$ when needed. Solutions containing $0.1,0.5$, and $1.0 \%$ (wt/wt) of CNCs were prepared following a similar procedure previously described [52]. Briefly, the CNC powder was first immersed in water and homogenized at 15,000 rpm for $3 \mathrm{~min}$ with a T25 digital Ultraturrax from IKA ${ }^{\circledR}$ (Staufen, Germany). Thereafter, the resultant dispersion was added to the polymer solution according to the compositions described above.

\subsection{Characterization of the Solutions}

All the prepared $\mathrm{EVOH}_{44}$ solutions, prior to electrospinning, were characterized in terms of viscosity, surface tension, and conductivity. A rotational viscosity meter Visco BasicPlus L (Fungilab S.A., San Feliu de Llobregat, Spain) with a low-viscosity adapter (LCP) was used to measure the apparent viscosity ( $\eta \mathrm{a})$, which was performed at $100 \mathrm{~s}^{-1}$. The Wilhemy plate method was followed to determine the surface tension with an EasyDyne K20 tensiometer (Krüss GmbH, Hamburg, Germany). Finally, a conductivity meter XS Con6 (Lab-box, Barcelona, Spain) was employed to evaluate the solution conductivity. Three replicates were carried out for each measurement. 


\subsection{Electrospinning Process}

The electrospinning setup used consisted of an Fluidnatek ${ }^{\circledR}$ LE-10 commercial lab equipment manufactured by Bioinicia S.L. (Valencia, Spain). The equipment was operated at environmental conditions of $25{ }^{\circ} \mathrm{C}$ and $40 \%$ relative humidity $(\mathrm{RH})$ with a motorized single needle injector, scanning horizontally towards a metallic fixed collector to obtain homogeneous depositions. High-content vinyl-alcohol EVOH copolymers have been reported to be relatively easy to electrospin, but the one selected in this work (with $44 \mathrm{~mol} \%$ ethylene) proved difficult to process due to very fast drying at the tip of the nozzle. To prevent needle clogging, a coaxial setup was used where pure 2-propanol was fluxed through the exterior needle to create a solvent jacket around the tip, as previously reported by Yu et al. [65]. In this setup, the sheath fluid flow-rate and the polymer solutions flowrates were found optimal at $250 \mu \mathrm{L} / \mathrm{h}$ and $6 \mathrm{~mL} / \mathrm{h}$, respectively. A voltage of $24 \mathrm{kV}$ and a distance between the tip and collector of $21 \mathrm{~cm}$ were set.

\subsection{Film Preparation}

The obtained EVOH mats were then converted into continuous fiber-based films by annealing below the polymer melting point in a 4122-model press from Carver, Inc. (Wabash, IN, USA). This post-processing was performed across the temperature range from 110 to $155^{\circ} \mathrm{C}$, for $15 \mathrm{~s}$. The average thickness of all the attained films was approximately $30 \mu \mathrm{m}$ and they were stored in a desiccator at $0 \% \mathrm{RH}$ before characterization.

\subsection{Characterization of the Films}

\subsubsection{Electron Microscopy}

For the observation of the CNCs as well as fiber and film morphologies, an S-4800 scanning electron microscopy (SEM) instrument from Hitachi (Tokyo, Japan) was used. Prior to this, both the electrospun $\mathrm{EVOH}_{44}$ fibers and their resultant films were fixed to beveled holders using conductive double-sided adhesive tape and sputtered with a mixture of gold-palladium under vacuum. For the cross-section observations, the films were cryofractured by immersion in liquid nitrogen. In all cases, an accelerating voltage of $10 \mathrm{kV}$ was used. The estimation of the dimensions was performed by means of the Aperture software from Apple (Cupertino, CA, USA) using a minimum of 20 SEM micrographs in their original magnification.

Transmission electron microscopy (TEM) was also performed to further study the distribution of $\mathrm{CNCs}$ in the $\mathrm{EVOH}_{44}$ fibers using a JEOL 1010 from JEOL USA, Inc. (Peabody, MA, USA) with an accelerating voltage of $100 \mathrm{kV}$.

\subsubsection{Transparency}

The light transmission of the films was determined using $50 \mathrm{~mm} \times 30 \mathrm{~mm}$ specimens in an ultraviolet-visible (UV-vis) spectrophotometer VIS3000 (Dinko Instruments, Barcelona, Spain). The absorption of light was quantified at wavelengths in the $200-700 \mathrm{~nm}$ range. Equation (1) [66] and Equation (2) [67] were followed to determine the values of transparency $(\mathrm{T})$ and opacity $(\mathrm{O})$, respectively:

$$
\begin{gathered}
\mathrm{T}=\frac{\mathrm{A}_{600}}{\mathrm{~L}} \\
\mathrm{O}=\mathrm{A}_{500} \times \mathrm{L}
\end{gathered}
$$

in which $A_{600}$ and $A_{500}$ correspond to the absorbance values at 600 and $500 \mathrm{~nm}$, respectively, whereas $\mathrm{L}$ represents the film thickness $(\mathrm{mm})$.

\subsubsection{Color}

The color of the films was estimated using a Chroma Meter CR-400 (Konica Minolta, Tokyo, Japan) with the D65 illuminant. The color difference $\left(\Delta \mathrm{E}^{*}\right)$ between the samples with CNCs and the neat $\mathrm{EVOH}_{44}$ was determined by the Equation (3) [68]: 


$$
\Delta \mathrm{E}^{*}=\left[\left(\Delta \mathrm{L}^{*}\right)^{2}+\left(\Delta \mathrm{a}^{*}\right)^{2}+\left(\Delta \mathrm{b}^{*}\right)^{2}\right]^{0.5}
$$

in which $\Delta \mathrm{L}^{*}$ represents the difference in terms of lightness from black to white, whereas $\Delta \mathrm{a}^{*}$ and $\Delta \mathrm{b}^{*}$ correspond to the differences in color, from green to red and blue to yellow, respectively. Color changes were assessed using a previous grading: Unnoticeable $\left(\Delta \mathrm{E}^{*}<1\right)$, only an experienced observer can notice the difference $\left(\Delta \mathrm{E}^{*} \geq 1\right.$ and $\left.<2\right)$, an unexperienced observer notices the difference $\left(\Delta \mathrm{E}^{*} \geq 2\right.$ and $\left.<3.5\right)$, clear noticeable difference $\left(\Delta \mathrm{E}^{*} \geq 3.5\right.$ and $\left.<5\right)$, and the observer notices different colors $\left(\Delta \mathrm{E}^{*} \geq 5\right)$ [69].

\subsubsection{Thermal Analysis}

Thermal transitions were studied using differential scanning calorimetry (DSC) on a DSC-7 analyzer from PerkinElmer, Inc. (Waltham, MA, USA), equipped with a cooling accessory Intracooler 2 also from PerkinElmer, Inc. A two-step program, with heating and cooling rates of $10^{\circ} \mathrm{C} / \mathrm{min}$ and a nitrogen atmosphere with a flow-rate of $20 \mathrm{~mL} / \mathrm{min}$, was applied. It consisted of a first heating step from -30 to $180^{\circ} \mathrm{C}$, followed by one minute isotherm at $180^{\circ} \mathrm{C}$ and a cooling run back to $-30^{\circ} \mathrm{C}$. All tests were carried out in triplicate and sample weights were of ca. $3 \mathrm{mg}$. An empty aluminum pan was used as reference. Calibration was performed using an indium sample and the thermograms were corrected with those of an empty pan. The glass transition temperature $\left(\mathrm{T}_{\mathrm{g}}\right), \mathrm{T}_{\mathrm{m}}$, and enthalpy of melting $\left(\Delta \mathrm{H}_{\mathrm{m}}\right)$ were obtained from the heating scans, while the crystallization temperature from the melt $\left(\mathrm{T}_{\mathrm{C}}\right)$ and enthalpy of crystallization $\left(\Delta \mathrm{H}_{\mathrm{C}}\right)$ were determined from the cooling scans. The enthalpies were normalized to the actual polymer content in the composites. The $\mathrm{EVOH}_{44}$ crystallinity content $\left(\chi_{c}\right)$ was estimated according to Equation (4) [7]:

$$
\chi_{\mathrm{c}}(\%)=\frac{1}{\left(1-\mathrm{m}_{\mathrm{f}}\right)}\left[\frac{\Delta \mathrm{Hm}-\Delta \mathrm{Hcc}}{\Delta \mathrm{Hm}_{0}}\right] \times 100
$$

where $\Delta \mathrm{H}_{\mathrm{m}}$ is the enthalpy for melting, $\Delta \mathrm{H}_{\mathrm{m} 0}$ is melting enthalpy for a $100 \%$ crystalline EVOH sample and $\left(1-\mathrm{m}_{\mathrm{f}}\right)$ is the weight fraction of $\mathrm{EVOH}_{44}$ in the sample. The $\Delta \mathrm{H}_{\mathrm{m} 0}$ value of $\mathrm{EVOH}_{44}$ was calculated following Equation (5) [70]:

$$
\Delta \mathrm{H}_{\mathrm{m} 0}=\alpha \Delta \mathrm{H}_{\mathrm{m} 0}^{\mathrm{PVA}}+\beta \Delta \mathrm{H}_{\mathrm{m} 0}^{\mathrm{PE}}
$$

where $\Delta \mathrm{H}_{\mathrm{m} 0} \mathrm{PVA}$ is enthalpy of melting for a $100 \%$ crystalline poly(vinyl alcohol) (PVOH), taken as $169.2 \mathrm{~J} \mathrm{~g}^{-1}$, and $\Delta \mathrm{H}_{\mathrm{m} 0}{ }^{\mathrm{PE}}$ is enthalpy of melting for a $100 \%$ crystalline of polyethylene (PE), taken as $290.0 \mathrm{~J} \mathrm{~g}^{-1}$, whereas $\alpha$ and $\beta$ correspond to the weight fractions of vinyl alcohol $(\alpha=0.56)$ and ethylene $(\beta=0.44)$ in $\mathrm{EVOH}_{44}$.

Thermogravimetric analysis (TGA) was performed in a TG-STDA model TGA/STDA851e/ LF/1600 thermobalance from Mettler-Toledo, LLC (Columbus, OH, USA), under a nitrogen flow-rate of $50 \mathrm{~mL} / \mathrm{min}$. The samples, with a weight of about $15 \mathrm{mg}$, were heated from 50 to $900{ }^{\circ} \mathrm{C}$ at a heating rate of $10{ }^{\circ} \mathrm{C} / \mathrm{min}$. The onset degradation temperature, measured at the temperature corresponding to a $5 \%$ weight loss $\left(\mathrm{T}_{5 \%}\right)$ and the thermal degradation temperature $\left(\mathrm{T}_{\mathrm{deg}}\right)$ were determined.

\subsubsection{ATR-FTIR Spectroscopy}

Fourier transform infrared spectroscopy (FTIR) single spectra were collected in the $600-4000 \mathrm{~cm}^{-1}$ wavelength range using the Tensor 37 FTIR equipment (Bruker, Germany) coupled to the attenuated total reflection (ATR) accessory Golden Gate (Specac, Ltd., Orpington, UK). Spectra were taken by averaging 20 scans at a resolution of $4 \mathrm{~cm}^{-1}$.

A Nicolet Nexus FTIR instrument (Thermo Fisher Scientific, Wilmington, DE, USA) coupled to a variable-temperature single reflection diamond ATR sampling accessory (Specac Ltd., Orpington, UK) was used to collect spectra as a function of temperature. Spectra were collected using the blank ATR crystal at the same temperature as the background by averaging 64 scans at $4 \mathrm{~cm}^{-1}$ resolution. The samples were clamped directly onto the ATR crystal using a calibrated torque wrench (Specac Ltd.) set at $80 \mathrm{cNm}$, which applies a 
load of $350 \mathrm{~N}$ via the sample accessory anvil, to ensure that any peak intensity changes in the data represented changes to the morphology of the samples. Prior to conducting the variable temperature infrared measurements, reproducibility of the sample contact and resulting spectra intensity were validated. Spectra were collected from 30 to $130{ }^{\circ} \mathrm{C}$ at $10{ }^{\circ} \mathrm{C}$ intervals and, thereafter, up to $200{ }^{\circ} \mathrm{C}$ at $5^{\circ} \mathrm{C}$ intervals. Spectra were not collected until the digital reading on the temperature controller had fully stabilized to ensure the validity of the selected temperature.

\subsubsection{Mechanical Tests}

The ASTM standard method D638 was followed to determine the mechanical properties of the films using an Instron 4400 universal testing machine from Instron (Norwood, MA, USA) equipped with a 1-kN load cell. Tensile tests of the films were performed with $115 \times 16 \mathrm{~mm}^{2}$ stamped dumb-bell shaped specimens using a cross-head speed of $10 \mathrm{~mm} / \mathrm{min}$ at room conditions. The samples were, prior to tensile assay, conditioned at $40 \% \mathrm{RH}$ and $25^{\circ} \mathrm{C}$ for $24 \mathrm{~h}$. At least six specimens were measured for each sample.

\subsubsection{Permeability Tests}

The water vapor permeability (WVP) of the films was determined following the standardized gravimetric method ASTM E96-95. Payne permeability cups of $3.5 \mathrm{~cm}$ of diameter from Elcometer Sprl (Hermallesous-Argenteau, Belgium) were used with $5 \mathrm{~mL}$ of distilled water. The testing was done at $25{ }^{\circ} \mathrm{C}$ on films exposed to $100 \% \mathrm{RH}$ placed within a desiccator containing dried silica gel that generated $0 \% \mathrm{RH}$. Cups with aluminum films were used as control samples to estimate solvent loss through the sealing. The cups were weighted daily using an analytical balance $( \pm 0.0001 \mathrm{~g})$. WVP was calculated from the regression analysis of weight loss data vs. time and the weight loss was calculated as the total loss minus the loss through the sealing. The permeability was obtained by multiplying the permeance by the film thickness.

The oxygen permeability (OP) was determined in duplicate at $0,20 \%$ and $80 \% \mathrm{RH}$ and $25{ }^{\circ} \mathrm{C}$, using an Oxygen Permeation Analyzer M8001 (Systech Illinois, Thame, UK) with temperature and $\mathrm{RH}$ control, purged with nitrogen before exposure to an oxygen flow of $10 \mathrm{~mL} / \mathrm{min}$. The tested area was $5 \mathrm{~cm}^{2}$.

\subsection{Statistical Analysis}

The software packaging STATGRAPHICS Centurion XVI v 16.1.03 (StatPoint Technologies, Inc., Warrenton, VA, USA) was used to evaluate the differences among the samples by analysis of variance (ANOVA). Fisher's least significant difference (LSD) was set at the $95 \%$ confidence level $(p<0.05)$.

\section{Results and Discussion}

\subsection{Solution Properties and Morphology}

The properties of the $\mathrm{EVOH}_{44}$ solution and its suspensions with CNCs were characterized to assess their processability by electrospinning. Table 1 summarizes the values obtained for each solution. The pure $\mathrm{EVOH}_{44}$ solution presented a viscosity of $71.9 \mathrm{cP}$, a surface tension of $23.8 \mathrm{mN} / \mathrm{m}$, and a conductivity of $11.63 \mu \mathrm{S} / \mathrm{cm}$. When CNCs was added to the solutions, their properties varied slightly, though the differences were still significant. Thus, for contents of $0.1,0.5$, and $1.0 \mathrm{wt} \%$ of $\mathrm{CNCs}$ in the $\mathrm{EVOH}_{44}$ solutions, the values for viscosity, surface tension, and conductivity were in the range of $74-80 \mathrm{cP}, 24-25 \mathrm{mN} / \mathrm{m}$, and $11.8-12.1 \mu \mathrm{S} / \mathrm{cm}$. The slight increase in viscosity can be related to the presence of the nanofiller in the suspensions, which could stablish secondary bonding interactions with the $\mathrm{EVOH}_{44}$ molecules via the hydroxyl groups. Similarly, the slight increase in surface tension and conductivity may be related to the higher polarity of the nanocellulose particles. Changes in the electrospun morphologies of EVOH due to variations in solution properties have been previously studied [71]. In particular, a decrease in the diameter of EVOH fibers was reported when the solution conductivity decreased. 
Table 1. Properties of the poly(ethylene-co-vinyl alcohol) with $44 \mathrm{~mol} \%$ of ethylene $\left(\mathrm{EVOH}_{44}\right)$ solution and suspensions, with cellulose nanocrystals (CNCs), and mean diameter of their corresponding electrospun fibers and beaded regions.

\begin{tabular}{cccccc}
\hline Sample & Viscosity $(\mathbf{c P})$ & $\begin{array}{c}\text { Surface Tension } \\
(\mathbf{m N} / \mathbf{m})\end{array}$ & $\begin{array}{c}\text { Conductivity } \\
(\mu \mathrm{S} / \mathbf{c m})\end{array}$ & $\begin{array}{c}\text { Mean Fiber } \\
\text { Diameter }(\mathbf{n m})\end{array}$ & $\begin{array}{c}\text { Mean Diameter of } \\
\text { Beaded Regions }(\mu \mathrm{\mu m})\end{array}$ \\
\hline $\mathrm{EVOH}_{44}$ & $71.9 \pm 1.2^{\mathrm{a}}$ & $23.8 \pm 0.1^{\mathrm{a}}$ & $11.63 \pm 0.03^{\mathrm{a}}$ & $410.0 \pm 128.0^{\mathrm{a}}$ & $1.1 \pm 0.2^{\mathrm{a}}$ \\
$\mathrm{EVOH}_{44}+0.1 \mathrm{wt} \% \mathrm{CNCs}$ & $74.3 \pm 0.8^{\mathrm{b}}$ & $24.1 \pm 0.4^{\mathrm{a}, \mathrm{b}}$ & $11.80 \pm 0.02^{\mathrm{a}, \mathrm{b}}$ & $410.4 \pm 99.4^{\mathrm{a}}$ & $1.3 \pm 0.3^{\mathrm{a}, \mathrm{b}}$ \\
$\mathrm{EVOH}_{44}+0.5 \mathrm{wt} \% \mathrm{CNCs}$ & $77.4 \pm 1.1^{\mathrm{c}}$ & $24.3 \pm 0.7^{\mathrm{a}, \mathrm{b}}$ & $12.00 \pm 0.05^{\mathrm{b}, \mathrm{c}}$ & $501.7 \pm 79.6^{\mathrm{a}}$ & $1.5 \pm 0.2^{\mathrm{a}, \mathrm{b}}$ \\
$\mathrm{EVOH}_{44}+1 \mathrm{wt} \% \mathrm{CNCs}$ & $80.1 \pm 0.7^{\mathrm{d}}$ & $24.9 \pm 0.5^{\mathrm{b}}$ & $12.10 \pm 0.03^{\mathrm{c}}$ & $592.4 \pm 102.9^{\mathrm{a}}$ & $1.8 \pm 0.1^{\mathrm{b}}$ \\
\hline
\end{tabular}

${ }^{a-d}$ Different letters in the same column mean significant difference among the samples $(p<0.05)$.

The morphology of the as-received CNC powder was observed by SEM. Figure 1 shows the SEM micrographs of the CNCs at both low and high magnification, that is, $400 \times($ Figure $1 \mathrm{a}$ ) and $3000 \times$ (Figure 1b), respectively. It can be observed that CNCs were mainly in the form of shrunken particles with a wide particle size distribution (Figure 1c). This particular type of morphology is known to occur during spray-drying due to the rapid evaporation of the solvent and the formation of an external crust during the first stages of drying, which collapses when the solvent present in the inner parts of the droplet evaporates and leads to a partial shrinkage of the particle [72]. It can also be observed that particle sizes varied from large particles of nearly $20 \mu \mathrm{m}$ down to nanoparticles below $100 \mathrm{~nm}$. A similar morphology, showing the co-presence of nanoparticles and large particles as a result of agglomeration has been previously reported for CNCs processed by spray-drying [73-75]. Agglomeration is produced during the drying process when the capillary, van der Waals, and hydrogen bonding forces overcome the electrostatic repulsion force produced by the negative charge on the surface of the CNCs [76]. The resulting powdered product obtained by the spray-drying technique, thus, consists of compact particles typically in the micro-size range.
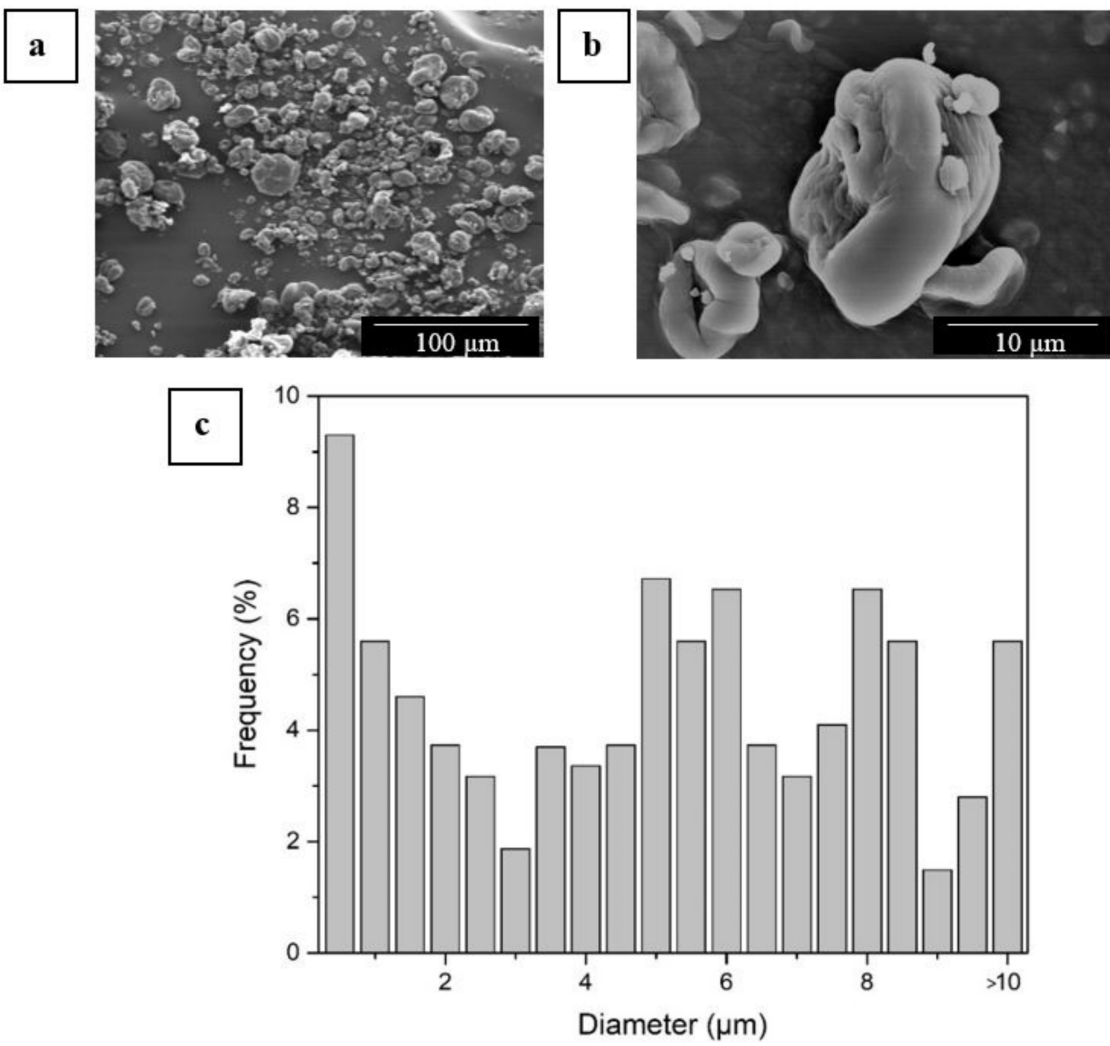

Figure 1. Scanning electron microscopy (SEM) images of the as-received cellulose nanocrystals (CNCs) in powder form taken at low (a) and high (b) magnification, showing scale markers of 100 and $10 \mu \mathrm{m}$, respectively; (c) Diameter histogram. 
The SEM images of the electrospun mats of the $\mathrm{EVOH}_{44}$ fibers, prior to the thermal post-treatment, are gathered in Figure 2. As it can be seen from these micrographs, all the mats, even those of neat $\mathrm{EVOH}_{44}$, presented some beads along the fiber axis. The beaded fiber morphology observed herein is similar to those observed in previous works reporting the preparation of electrospun fibers of EVOH with different contents of ethylene $[63,77]$. The presence of beads in the fibers are habitually associated to a non-optimal concentration of the polymer and/or of the operating parameters [78]. However, the concentration and parameters used resulted in successful electrospinning for this material. The mean diameters of the beaded regions increased with the CNCs content, in a range from 1.1 to $1.8 \mu \mathrm{m}$. As shown in previous Table 1, the mean diameter of the neat $\mathrm{EVOH}_{44}$ fibers obtained by electrospinning, included in Figure 2a, were around $410 \mathrm{~nm}$. The incorporation of CNCs resulted in an increase in the diameter of the $\mathrm{EVOH}_{44}$ fibers for contents above $0.5 \mathrm{wt} \%$. Thus, the samples with a $0.1 \mathrm{wt} \% \mathrm{CNCs}$ (see Figure $2 \mathrm{~b}$ ) exhibited fibers with similar size as the pure $\mathrm{EVOH}_{44}$, that is, $410 \mathrm{~nm}$, but with more beaded regions. In the case of the samples with 0.5 and $1.0 \mathrm{wt} \%$ of CNCs, gathered respectively in Figure $2 \mathrm{c}, \mathrm{d}$, the fibers showed mean diameters of approximately 502 and $592 \mathrm{~nm}$. This effect can be ascribed to the slight viscosity increase described above. This result differs from previous studies in which the presence of CNCs reduced fiber diameter due to an increase in conductivity as CNCs is negatively charged $[79,80]$. Moreover, the bigger beaded areas in the fibers could be generated to accommodate $\mathrm{CNCs}$ agglomerates.
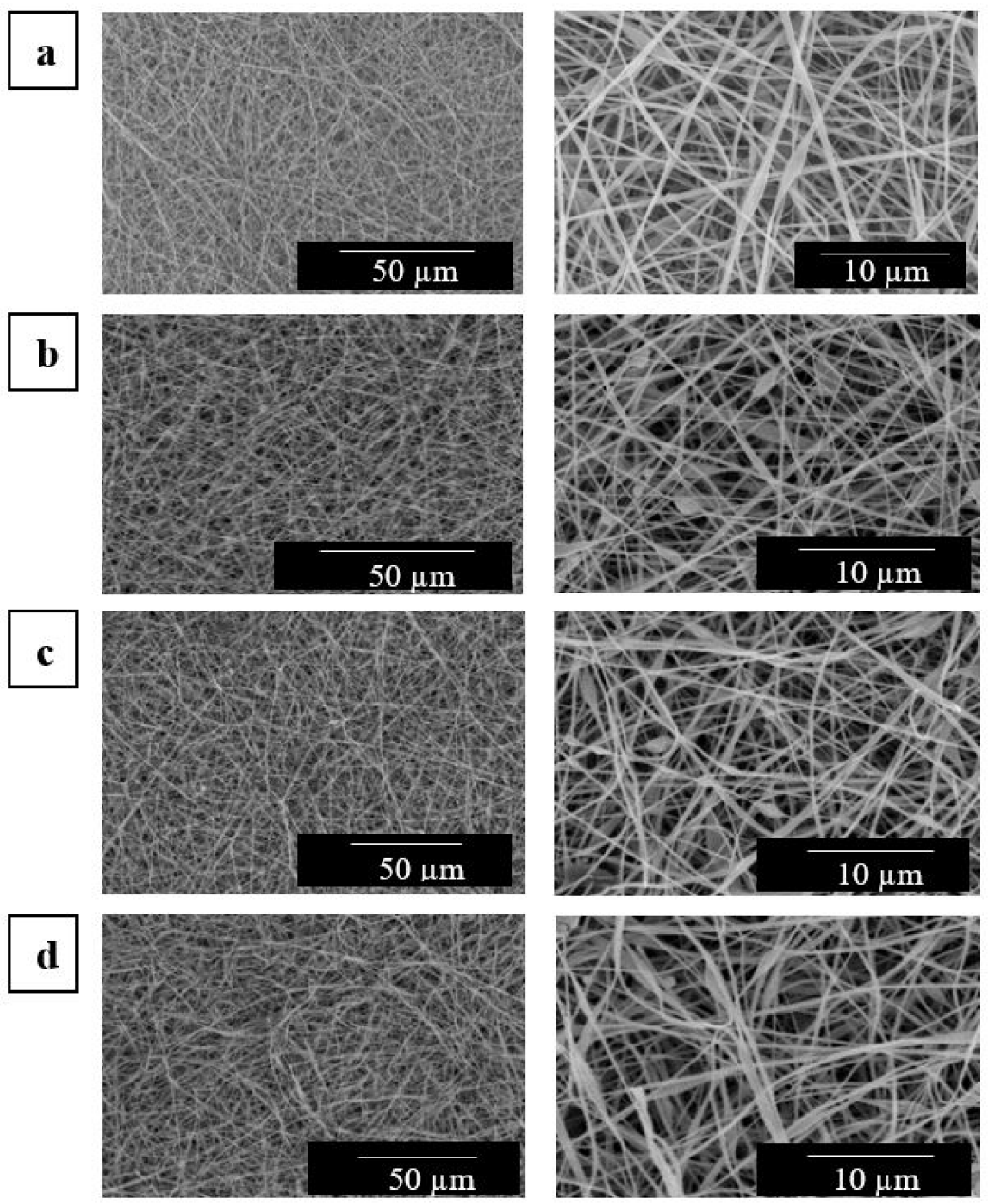

Figure 2. Scanning electron microscopy (SEM) images of the electrospun mats of poly(ethylene-covinyl alcohol) with $44 \mathrm{~mol} \%$ of ethylene $\left(\mathrm{EVOH}_{44}\right)$, pure (a) and with cellulose nanocrystals $(\mathrm{CNCs})$ : (b) $0.1 \mathrm{wt} \%$; (c) $0.5 \mathrm{wt} \%$; (d) $1.0 \mathrm{wt} \%$. Left images were taken $800 \times$ at with scale markers of $50 \mu \mathrm{m}$, while right images were taken at $3000 \times$ with scale markers of $10 \mu \mathrm{m}$. 
As a result of potential agglomeration of CNCs in the electrospun $\mathrm{EVOH}_{44}$ fiber beaded regions, the fibers were also observed by TEM. Figure 3 displays the TEM micrographs of the electrospun fibers, in which it can be discerned that the CNC distribution was highly dependent on the added content. For electrospun fibers with a content of $0.1 \mathrm{wt} \%$, shown in Figure 3a, the incorporated CNCs were relatively well distributed along the fiber axis since agglomerates are hard to spot. Figure $3 \mathrm{~b}$ reveals that the electrospun $\mathrm{EVOH}_{44}$ fibers with $0.5 \mathrm{wt} \%$ also showed a good distribution of CNCs. However, agglomeration was very noticeable in Figure 3c, in which it can be observed that CNCs at $1.0 \mathrm{wt} \%$ were mainly located in the beaded regions. Similar results have been observed previously for BCNWs incorporated into polyethylene oxide (PEO) fibers by electrospinning [81].

\section{a}

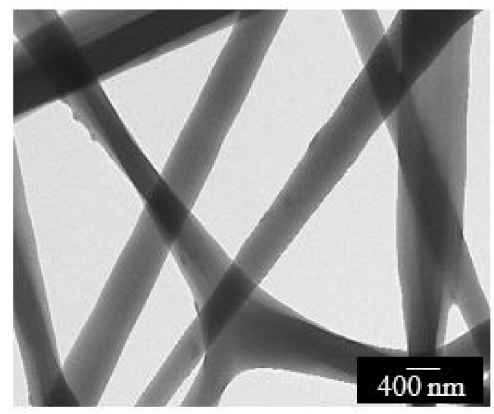

b

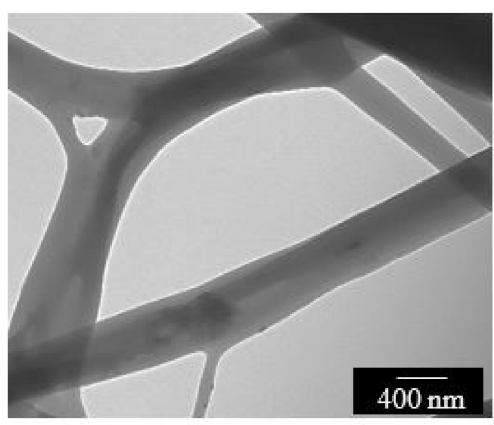

c

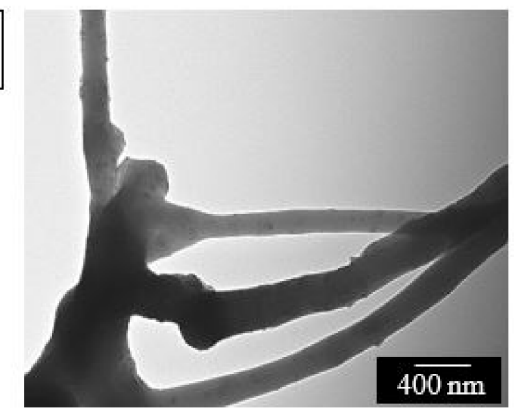

Figure 3. Transmission electron microscopy (TEM) images of the electrospun fibers of poly(ethyleneco-vinyl alcohol) with $44 \mathrm{~mol} \%$ of ethylene $\left(\mathrm{EVOH}_{44}\right)$ with cellulose nanocrystals (CNCs): (a) $0.1 \mathrm{wt} \%$; (b) $0.5 \mathrm{wt} \%$; (c) $1.0 \mathrm{wt} \%$. Images taken at 10,000 $\times$ with scale markers of $400 \mathrm{~nm}$.

\subsection{Thermal Properties of the Electrospun Fibers}

The DSC curves for the different electrospun $\mathrm{EVOH}_{44}$ fiber mats of the various materials, corresponding to the first heating and cooling steps, are gathered in Figure 4.

Table 2 displays the main thermal values obtained from the DSC curves. Regarding the neat $\mathrm{EVOH}_{44}$, one can observe in Figure 4a that, during the first heating, it showed a $\mathrm{T}_{\mathrm{g}}$ at approximately $41^{\circ} \mathrm{C}$. The low-intensity endothermic peak observed in the glass transition region is often connected with endothermic relaxation phenomena occurring at the transient state from glassy to rubbery for the amorphous phase. Then, the $\mathrm{EVOH}_{44}$ copolymer melted at nearly $164^{\circ} \mathrm{C}$ with a $\Delta \mathrm{H}_{\mathrm{m}}$ of $60.1 \mathrm{~J} / \mathrm{g}$, resulting in a crystallinity degree of $27.0 \%$. 
In relation to the $\mathrm{EVOH}_{44}$ composites, the $\mathrm{T}_{\mathrm{g}}$ values increased in temperature, ranging between $41.7-44.0^{\circ} \mathrm{C}$, suggesting a filler-induced "rigidization" of the amorphous phase. This effect was seen maximum for the sample with the highest dispersed amount of CNCs, that is, $1 \mathrm{wt} \%$. The fibers of the nanocomposites also exhibited a somewhat broader melting endothermic events towards lower temperatures than the pristine polymer. Thus, the melting points and enthalpies were seen to decrease with increasing filler content, suggesting a crystallinity distortion induced by the filler. More specifically, the $\mathrm{T}_{\mathrm{m}}$ of $\mathrm{EVOH}_{44}$ was reduced by $7.1{ }^{\circ} \mathrm{C}$ in the nanocomposite with $1 \mathrm{wt} \% \mathrm{CNCs}$, and the crystallinity decreased to $23.4 \%, 24.1 \%$, and $22.8 \%$ for the $0.1,0.5$, and $1.0 \mathrm{wt} \% \mathrm{CNC}$ content, respectively. In this regard, it is interesting to mention that Martínez-Sanz et al. [52] also reported a decrease in $\mathrm{T}_{\mathrm{m}}$ by adding $\mathrm{BCNW}$ s to electrospun $\mathrm{EVOH}_{29}$ fibers. Alterations in crystallinity have been linked to a covalent or hydrogen bonding between the $\mathrm{EVOH}$ hydroxyl groups $(\mathrm{OH})$ and low-molecular weight $\left(\mathrm{M}_{\mathrm{W}}\right)$ additives in the amorphous phase [82].
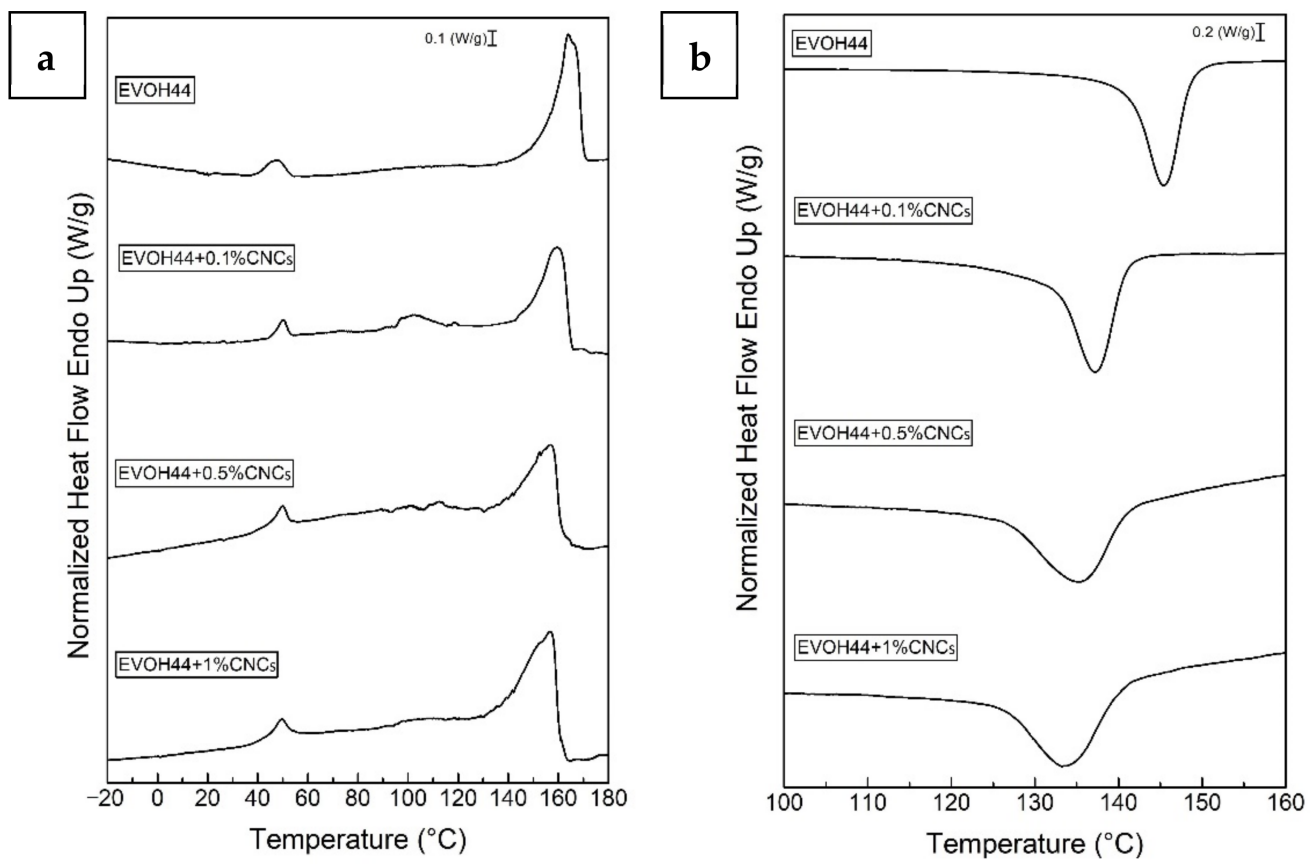

Figure 4. Differential scanning calorimetry (DSC) curves during first heating (a) and cooling (b) of the electrospun fibers of poly(ethylene-co-vinyl alcohol) with $44 \mathrm{~mol} \%$ of ethylene $\left(\mathrm{EVOH}_{44}\right)$ with and without cellulose nanocrystals (CNCs).

Figure $4 \mathrm{~b}$ also shows that in agreement with the melting data, the neat $\mathrm{EVOH}_{44}$ showed during crystallization a $\mathrm{T}_{\mathrm{c}}$ value centered at $145.4^{\circ} \mathrm{C}$ and a $\Delta \mathrm{H}_{\mathrm{c}}$ value of $61.8 \mathrm{~J} / \mathrm{g}$, that decreased and broadened with increasing the filler content. In particular, the lowest $\mathrm{T}_{\mathrm{c}}$ value was observed for the nanocomposite sample with $1 \mathrm{wt} \% \mathrm{CNCs}$, with a reduction of $12.2{ }^{\circ} \mathrm{C}$. Thus, the presence of CNCs impedes the proper lateral order of the copolymer chains, requiring higher undercoolings to crystallize, and doing so to a lesser extent than in the unfilled material. 
Table 2. Thermal properties of the electrospun poly(ethylene-co-vinyl alcohol) with $44 \mathrm{~mol} \%$ of ethylene $\left(\mathrm{EVOH}_{44}\right)$ fibers with and without cellulose nanocrystals (CNCs) in terms of: glass transition temperature $\left(\mathrm{T}_{\mathrm{g}}\right)$, melting temperature ( $\left.\mathrm{T}_{\mathrm{m}}\right)$, enthalpy of melting $\left(\Delta \mathrm{H}_{\mathrm{m}}\right)$ and crystallinity $\left(\% \mathrm{X}_{\mathrm{c}}\right)$, crystallization temperature $\left(\mathrm{T}_{\mathrm{c}}\right)$ and enthalpy of crystallization $\left(\Delta \mathrm{H}_{\mathrm{c}}\right)$.

\begin{tabular}{|c|c|c|c|c|c|}
\hline \multirow{2}{*}{ Sample } & \multicolumn{3}{|c|}{ First Heating } & \multicolumn{2}{|c|}{ Cooling } \\
\hline & $\mathrm{T}_{\mathrm{g}}\left({ }^{\circ} \mathrm{C}\right)$ & $\mathrm{T}_{\mathrm{m}}\left({ }^{\circ} \mathrm{C}\right)$ & $\Delta H_{m}(J / g)\left(\% X_{c}\right)$ & $\mathrm{T}_{\mathrm{c}}\left({ }^{\circ} \mathrm{C}\right)$ & $\Delta \mathbf{H}_{\mathrm{c}}(\mathrm{J} / \mathrm{g})$ \\
\hline $\mathrm{EVOH}_{44}$ & $40.6 \pm 0.3^{a}$ & $163.9 \pm 1.2^{\mathrm{a}}$ & $60.1 \pm 2.1^{\mathrm{a}}(27.0)$ & $145.4 \pm 0.8^{\mathrm{a}}$ & $61.8 \pm 2.1^{\mathrm{a}}$ \\
\hline $\mathrm{EVOH}_{44}+0.1 \mathrm{wt} \% \mathrm{CNCs}$ & $44.0 \pm 0.5^{b}$ & $160.1 \pm 2.2^{b}$ & $52.0 \pm 1.0^{\mathrm{b}}(23.4)$ & $137.2 \pm 0.3^{b}$ & $50.1 \pm 1.1^{b}$ \\
\hline $\mathrm{EVOH}_{44}+0.5 \mathrm{wt} \% \mathrm{CNCs}$ & $42.5 \pm 0.7^{c}$ & $157.2 \pm 1.4^{\mathrm{b}}$ & $53.4 \pm 2.4^{\mathrm{b}}(24.1)$ & $135.3 \pm 1.0^{\mathrm{c}}$ & $44.2 \pm 1.5^{\mathrm{c}}$ \\
\hline $\mathrm{EVOH}_{44}+1.0$ wt $\% \mathrm{CNCs}$ & $41.7 \pm 0.2^{\mathrm{c}}$ & $156.8 \pm 1.6^{\mathrm{b}}$ & $50.1 \pm 1.1^{\mathrm{b}}(22.8)$ & $133.2 \pm 0.5^{\mathrm{d}}$ & $38.5 \pm 1.4^{\mathrm{d}}$ \\
\hline
\end{tabular}

${ }^{a-d}$ Different letters in the same column mean significant difference among the samples $(p<0.05)$.

The results obtained for the here-prepared electrospun $\mathrm{EVOH}_{44}$ fibers agree reasonably well with those reported in the literature for materials produced by other techniques. For instance, $\mathrm{EVOH}_{44}$ films obtained by extrusion showed $\mathrm{T}_{\mathrm{m}}$ values around $160{ }^{\circ} \mathrm{C}$ and $162{ }^{\circ} \mathrm{C}$, during the first and second heating, respectively [83]. In another study, $\mathrm{EVOH}_{44}$ films prepared by solvent casting presented a $\mathrm{T}_{\mathrm{C}}$ of $140^{\circ} \mathrm{C}$ and $\mathrm{T}_{\mathrm{m}}$ values of $163^{\circ} \mathrm{C}$ and $165^{\circ} \mathrm{C}$, during the first and second heating, respectively [84]. Moreover, in the latter study, MFC was added to solvent-cast $\mathrm{EVOH}_{44}$ films, reporting also lower $\mathrm{T}_{\mathrm{c}}$ and $\mathrm{T}_{\mathrm{m}}$ values compared to the pristine copolymer.

\subsection{Film Forming by Interfiber Coalescence Induced by Annealing}

In order to induce fiber mat densification, different annealing temperatures below the copolymer melting point were screened to ascertain the most optimal thermal treatment that can lead to continuous fiber-based films better suited for their use in packaging. The morphology evolution of the electrospun materials obtained at different annealing temperatures is shown in Figure 5 from top views (Figure 5a) and cryo-fracture surfaces (Figure 5b). From this figure, it can be seen that at temperatures below $145^{\circ} \mathrm{C}$, the electrospun materials still showed some level of porosity and non-homogeneous surface. At $145{ }^{\circ} \mathrm{C}$ and $150{ }^{\circ} \mathrm{C}$, a compact interfiber coalescence of the $\mathrm{EVOH}_{44}$ fibers occurred, causing a material densification and alignment side by side of the fibers. At $155^{\circ} \mathrm{C}$, the continuous structure was lost due to the appearance of holes caused by partial melting of the copolymer. As a result, $145^{\circ} \mathrm{C}$ was selected as the minimum annealing temperature, below the melting point of $\mathrm{EVOH}_{44}$, to thermally process the material to turn it into a continuous film.

Similarly, the electrospun mats of $\mathrm{EVOH}_{44}$ with the different $\mathrm{CNC}$ contents were also annealed at $145^{\circ} \mathrm{C}$ and, thereafter, observed by SEM. The resulting morphology in both top view and cross-section of the materials, are presented in Figure 6. As it can be seen, homogeneous fiber-based films were obtained in all cases.

Furthermore, the distribution of the CNCs in the electrospun biopapers of $\mathrm{EVOH}_{44}$ was also analyzed by TEM. In Figure 7, it can be seen that, as was previously observed in the electrospun fibers, the CNC distribution was better at both 0.1 wt \% (Figure 7a) and 0.5 wt \% loadings (Figure $7 \mathrm{~b}$ ), whereas more nanocrystal aggregates were easily found at the highest content, that is, at $1.0 \mathrm{wt} \%$ (Figure 7c). These results suggest that the $\mathrm{CNC}$ distribution achieved in the $\mathrm{EVOH}_{44}$ fibers during electrospinning was seemingly preserved in the films. 


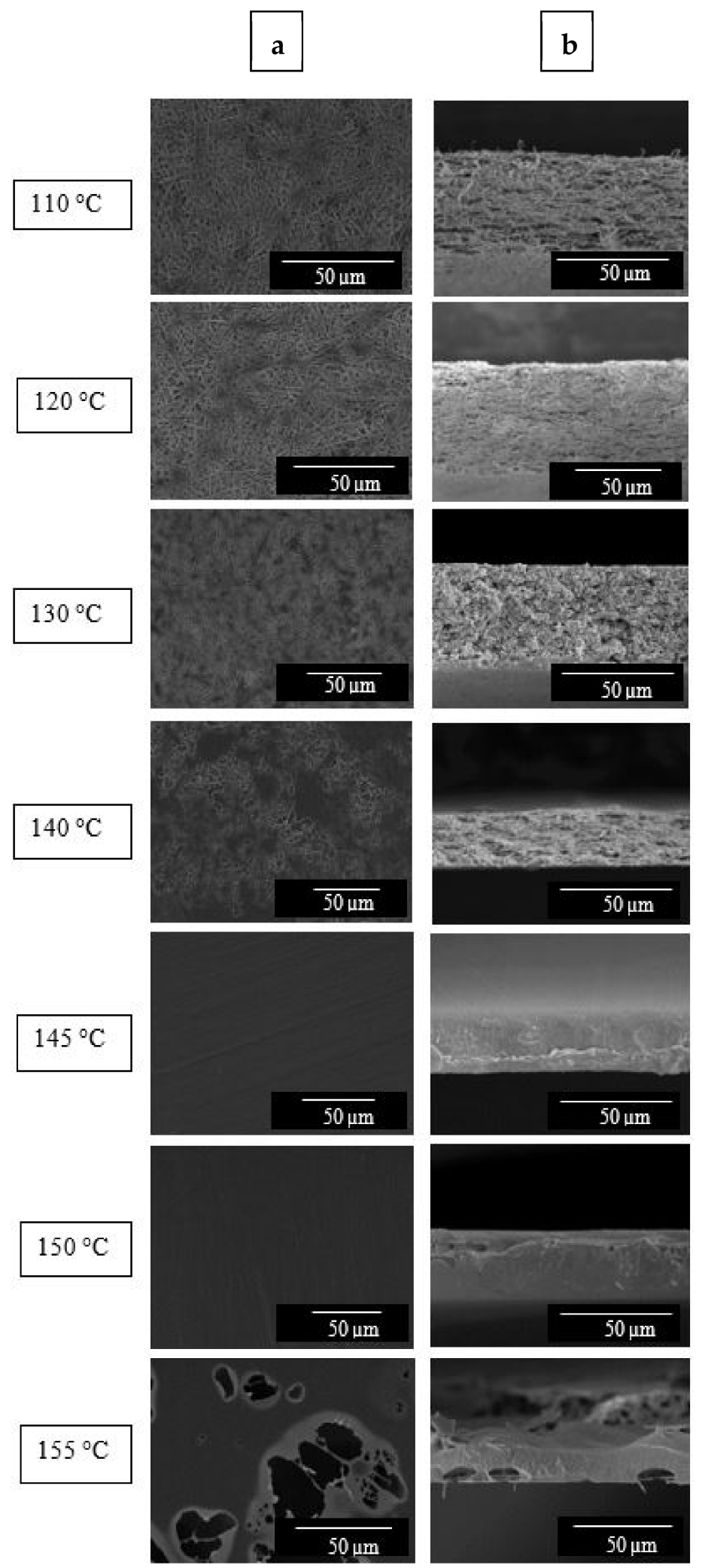

Figure 5. Scanning electron microscopy (SEM) images at the top view (a) and cross-section (b) of the electrospun mats of poly(ethylene-co-vinyl alcohol) with $44 \mathrm{~mol} \%$ of ethylene $\left(\mathrm{EVOH}_{44}\right)$ annealed at: $110,120,130,140,145,150$, and $155^{\circ} \mathrm{C}$ for $15 \mathrm{~s}$. Images were taken at $1100 \times$ with scale markers of $50 \mu \mathrm{m}$. 

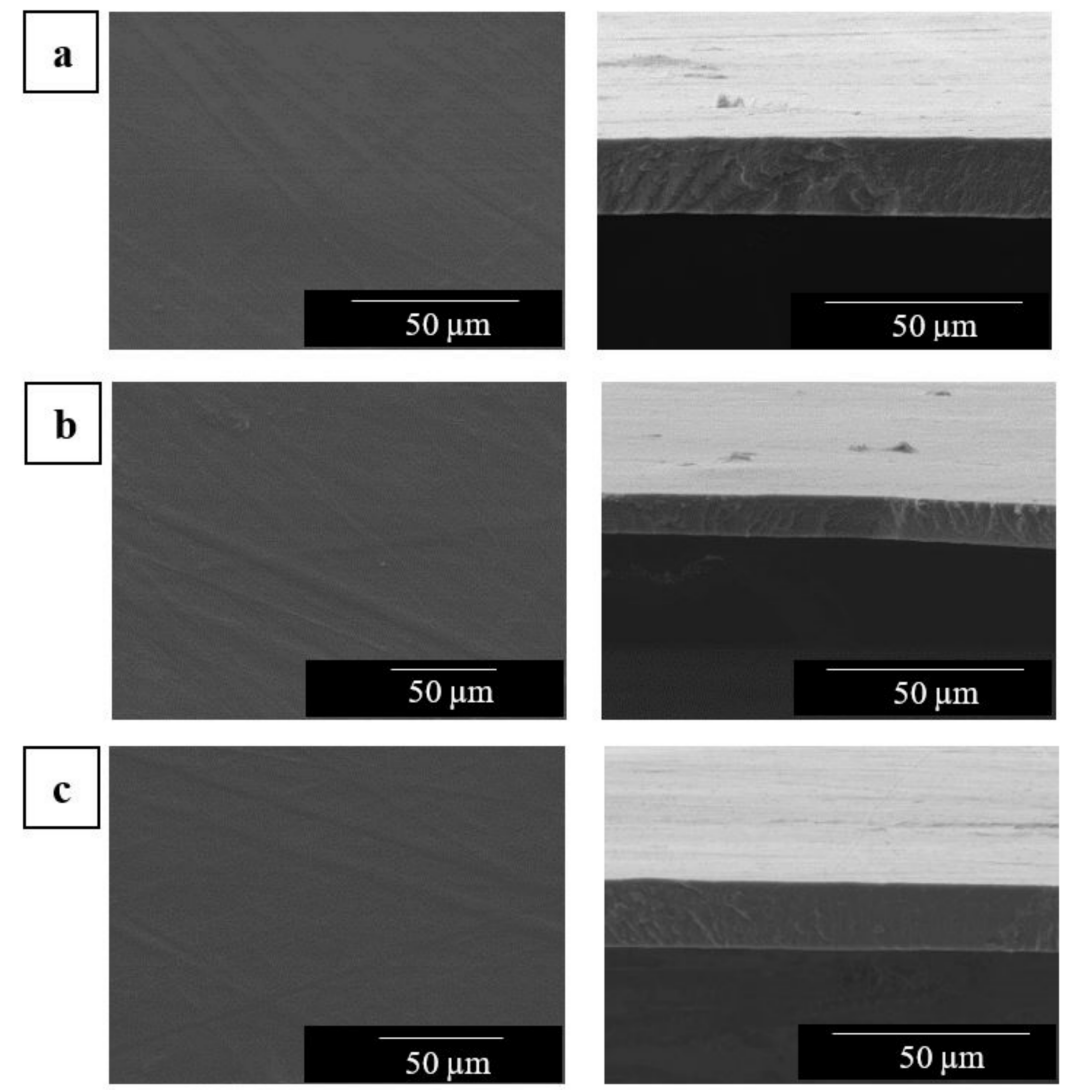

Figure 6. Scanning electron microscopy (SEM) images in top view (left) and cross-section (right) of the electrospun mats of poly(ethylene-co-vinyl alcohol) with $44 \mathrm{~mol} \%$ of ethylene $\left(\mathrm{EVOH}_{44}\right)$ with cellulose nanocrystals (CNCs): (a) $0.1 \mathrm{wt} \%$; (b) $0.5 \mathrm{wt} \%$; (c) $1.0 \mathrm{wt} \%$. The electrospun mats were thermally post-treated at $145^{\circ} \mathrm{C}$ for $15 \mathrm{~s}$. Images were taken at $1100 \times$ with scale markers are of $50 \mu \mathrm{m}$.
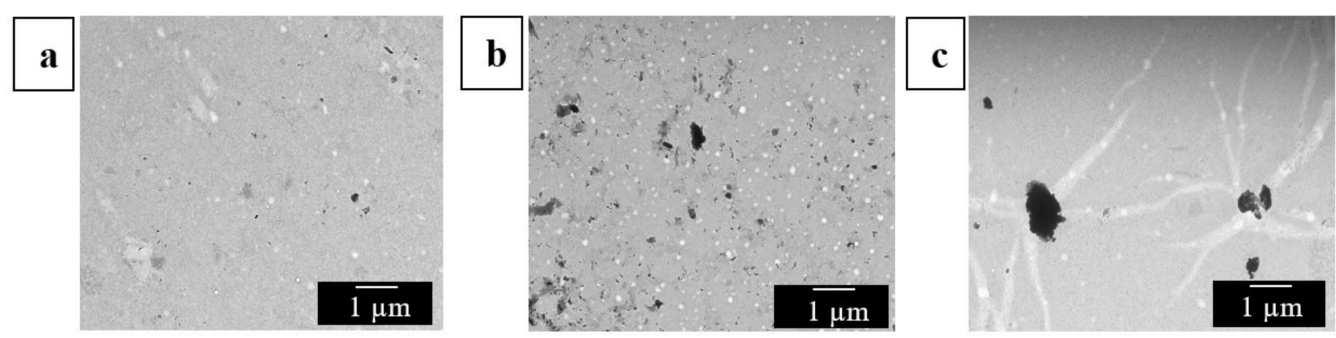

Figure 7. Transmission electron microscopy (TEM) images of the annealed electrospun films of poly(ethylene-co-vinyl alcohol) with $44 \mathrm{~mol} \%$ of ethylene $\left(\mathrm{EVOH}_{44}\right)$ with cellulose nanocrystals (CNCs): (a) $0.1 \mathrm{wt} \%$; (b) $0.5 \mathrm{wt} \%$; (c) $1.0 \mathrm{wt} \%$. Images were taken at $3000 \times$ with scale markers of $1 \mu \mathrm{m}$.

\subsection{Variable-Temperature FTIR Spectroscopy}

An insight into the spectral changes associated to the molecular order of the electrospun $\mathrm{EVOH}_{44}$ fibers was carried out by ATR-FTIR during heating from 30 to $200{ }^{\circ} \mathrm{C}$, as it can be seen in Figure 8.

One characteristic feature of the EVOH spectra is the peak centered at approximately $3330 \mathrm{~cm}^{-1}$, which corresponds to the stretching band of the $\mathrm{O}-\mathrm{H}$ oscillators [85]. The breadth and position of this band indicates the presence of strong hydrogen bonding within the copolymer, the broadness is due to intra- and intermolecular hydrogen-bonded $\mathrm{OH}$ dimer and multimers, with varying strengths and geometries [86,87]. In addition, the $\mathrm{EVOH}_{44}$ spectra showed bands at nearly 2933 and $2852 \mathrm{~cm}^{-1}$ corresponding to the 
$\mathrm{C}-\mathrm{H}$ antisymmetric and symmetric stretching vibrations, respectively. The features at approximately 1437 and $1456 \mathrm{~cm}^{-1}$ are attributed to $\mathrm{OH}$ deformation, the band at $1374 \mathrm{~cm}^{-1}$ is likely arising from $\mathrm{OH}$ deformation, and $\mathrm{CH}_{2}$ wagging and the band at $842 \mathrm{~cm}^{-1}$ is assigned to skeletal vibrations and $\mathrm{CH}_{2}$ rocking $[88,89]$.

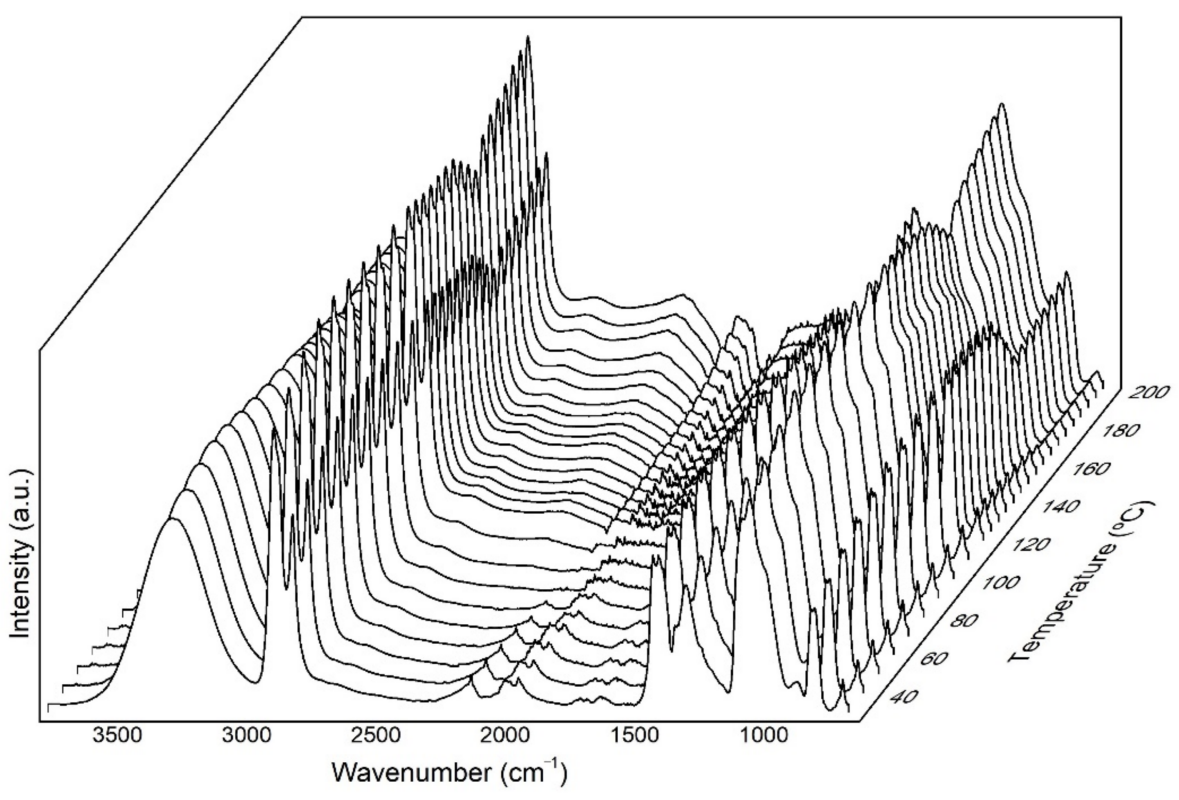

Figure 8. Fourier transform infrared spectroscopy (FTIR) spectra taken during heating of the electrospun fibers of poly(ethylene-co-vinyl alcohol) with $44 \mathrm{~mol} \%$ of ethylene $\left(\mathrm{EVOH}_{44}\right)$.

Many FTIR bands in polymers are conformationally sensitive, being the sharper peaks associated to ordered chain segments along the backbone, arising mostly from within crystals. When the relative intensity of conformationally sensitive bands rises upon heating, they typically sharpen, shifting in position and become narrower [57]. From Figure 8, a progressive increase in the intensity of many bands was initially observed, associated to classical crystal perfecting, followed by a leveling-off of these and a subsequent decrease up to around $160^{\circ} \mathrm{C}$. The steeper final drop in intensity observed is ascribed to the decrease in molecular order preceding to the melting of the sample. Therefore, at the selected annealing temperature of $145^{\circ} \mathrm{C}$, many of the bands in the spectra are in the regime in which they begin to decrease intensity, suggesting that the molecular order has started to decreased. Therefore, at this temperature, enough thermally-induced molecular motions are enabled for the interfiber coalescence process to occur, being able to reduce the high surface energy of the fibers.

\subsection{Optical Properties of the Annealed Electrospun Films}

The contact transparency pictures of the films are gathered in Figure 9. From this figure, it can be seen that, regardless of the $\mathrm{CNC}$ content, all the $\mathrm{EVOH}_{44}$ film samples presented high contact transparency. Similar good optical properties have been reported earlier for electrospun fibers subjected to interfiber coalescence by annealing [71,77]. Table 3 shows that the color parameters changed slightly between the different samples, in most cases being not significant, showing values ranging between $2.79-2.84,-4.69-(-5.10)$, and 90.84-91.28, for the $\mathrm{a}^{*}, \mathrm{~b}^{*}$, and $\mathrm{L}^{*}$, respectively. This implies that all the films were luminous with a slight tendency towards red and blue colors. In terms of color difference, the film samples with CNCs showed a $\Delta \mathrm{E}^{*}$ value $<1$, which indicates that the color change with respect to the neat $\mathrm{EVOH}_{44}$ film was unnoticeable. On the other hand, regarding transparency, it was observed that the $\mathrm{T}$ and $\mathrm{O}$ values decreased with increasing $\mathrm{CNC}$ content. Thus, the neat $\mathrm{EVOH}_{44}$ film and the composite film with $0.1 \mathrm{wt} \% \mathrm{CNCs}$ showed $\mathrm{T}$ values of 7.9 and 7.7, respectively. However, $\mathrm{EVOH}_{44}$ with 0.5 and $1.0 \mathrm{wt} \% \mathrm{CNCs}$ presented 
$\mathrm{T}$ values of 4.6 and 3.6, respectively. In terms of opacity, the $\mathrm{O}$ values slightly decreased from 0.004 to 0.002 . Since the color variations were minimal and the nanocomposite films preserved most of the high transparency of the $\mathrm{EVOH}_{44}$ film, it is inferred again the good distribution of the dispersed nanofillers across the copolymer matrix. Similar results were reported by Martinez-Sanz, after the incorporation of $\mathrm{BCNW}$ s into an $\mathrm{EVOH}_{29}$ matrix by electrospinning before melt-mixing. In the previous work, it was already demonstrated that this methodology can be an efficient process to disperse BCNWs, since the resultant nanocomposites exhibited higher transparency than the ones developed by direct meltmixing [52].
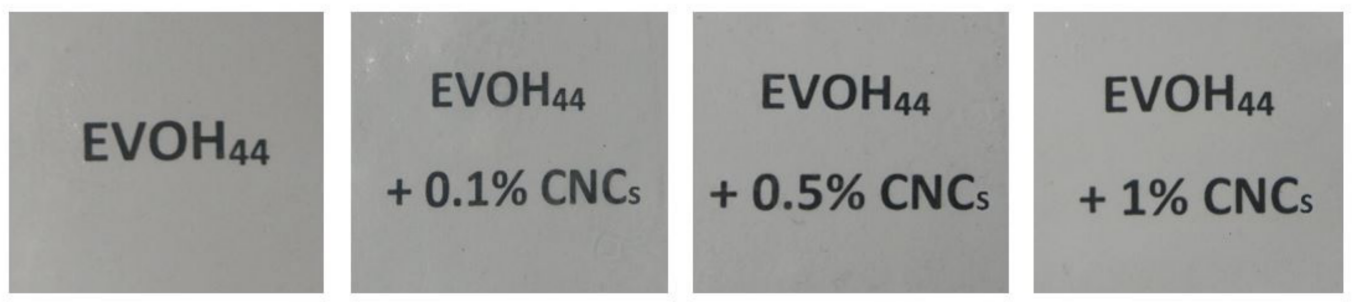

Figure 9. Contact transparency pictures of the annealed electrospun films of poly(ethylene-co-vinyl alcohol) with $44 \mathrm{~mol} \%$ of ethylene $\left(\mathrm{EVOH}_{44}\right)$ with and without cellulose nanocrystals (CNCs).

Table 3. Optical and color properties of the annealed electrospun films of poly(ethylene-co-vinyl alcohol) with $44 \mathrm{~mol} \%$ of ethylene $\left(\mathrm{EVOH}_{44}\right)$ with and without cellulose nanocrystals (CNCs).

\begin{tabular}{ccccccc}
\hline Film & $\mathbf{a}^{*}$ & $\mathbf{b}^{*}$ & $\mathbf{L}^{*}$ & $\boldsymbol{D E}^{*}$ & $\mathbf{T}$ & $\mathbf{O}$ \\
\hline $\mathrm{EVOH}_{44}$ & $2.81 \pm 0.02^{\mathrm{a}}$ & $-4.94 \pm 0.04^{\mathrm{a}}$ & $91.04 \pm 0.05^{\mathrm{a}}$ & - & $7.87 \pm 0.04^{\mathrm{a}}$ & $0.004 \pm 0.001^{\mathrm{a}}$ \\
$\mathrm{EVOH}_{44}+0.1 \mathrm{wt} \% \mathrm{CNCs}$ & $2.79 \pm 0.03^{\mathrm{a}}$ & $-4.69 \pm 0.03^{\mathrm{b}}$ & $91.28 \pm 0.03^{\mathrm{b}}$ & $0.35 \pm 0.03^{\mathrm{a}}$ & $7.70 \pm 0.03^{\mathrm{a}}$ & $0.003 \pm 0.002^{\mathrm{a}}$ \\
$\mathrm{EVOH}_{44}+0.5 \mathrm{wt} \% \mathrm{CNCs}$ & $2.81 \pm 0.01^{\mathrm{a}}$ & $-5.02 \pm 0.05^{\mathrm{a}, \mathrm{c}}$ & $90.92 \pm 0.04^{\mathrm{a}}$ & $0.14 \pm 0.04^{\mathrm{b}}$ & $4.64 \pm 0.02^{\mathrm{b}}$ & $0.002 \pm 0.001^{\mathrm{a}}$ \\
$\mathrm{EVOH}_{44}+1.0 \mathrm{wt} \% \mathrm{CNCs}$ & $2.84 \pm 0.02^{\mathrm{a}}$ & $-5.10 \pm 0.04^{\mathrm{c}}$ & $90.84 \pm 0.04^{\mathrm{a}}$ & $0.26 \pm 0.03^{\mathrm{a}, \mathrm{b}}$ & $3.61 \pm 0.03^{\mathrm{c}}$ & $0.002^{ \pm 0.001^{\mathrm{a}}}$ \\
\hline
\end{tabular}

$\mathrm{a}^{*}$ : red/green coordinates (+a red, -a green); $\mathrm{b}^{*}$ : yellow /blue coordinates (+b yellow, $-\mathrm{b}$ blue); $\mathrm{L}^{*}$ : Luminosity (+L luminous, $-\mathrm{L}$ dark); $\Delta \mathrm{E}^{*}:$ color differences; $\mathrm{T}$ : transparency; O: opacity. ${ }^{\mathrm{a}-\mathrm{c}}$ Different letters in the same column mean significant difference among the samples $(p<0.05)$.

\subsection{Thermal Stability of the Annealed Electrospun Films}

Figure 10 shows the TGA curves of the $\mathrm{CNC}$ powder and electrospun $\mathrm{EVOH}_{44}$ films, whereas Table 4 gathers the main TGA parameters. The CNCs presented a $\mathrm{T}_{5} \%$ at $215.6{ }^{\circ} \mathrm{C}$ and a $\mathrm{T}_{\mathrm{deg}}$ at $288.9^{\circ} \mathrm{C}$ with a mass loss of $41.3 \%$ and a residual mass of $5.8 \%$. These results are consistent with the existing literature for CNCs. For example, Mano et al. [90] showed that the main thermal degradation of $\mathrm{CNCs}$ occurred at about $277^{\circ} \mathrm{C}$. Similar results were reported by Cheng et al. [91], where CNCs presented a $\mathrm{T}_{\text {deg }}$ close to $300^{\circ} \mathrm{C}$.
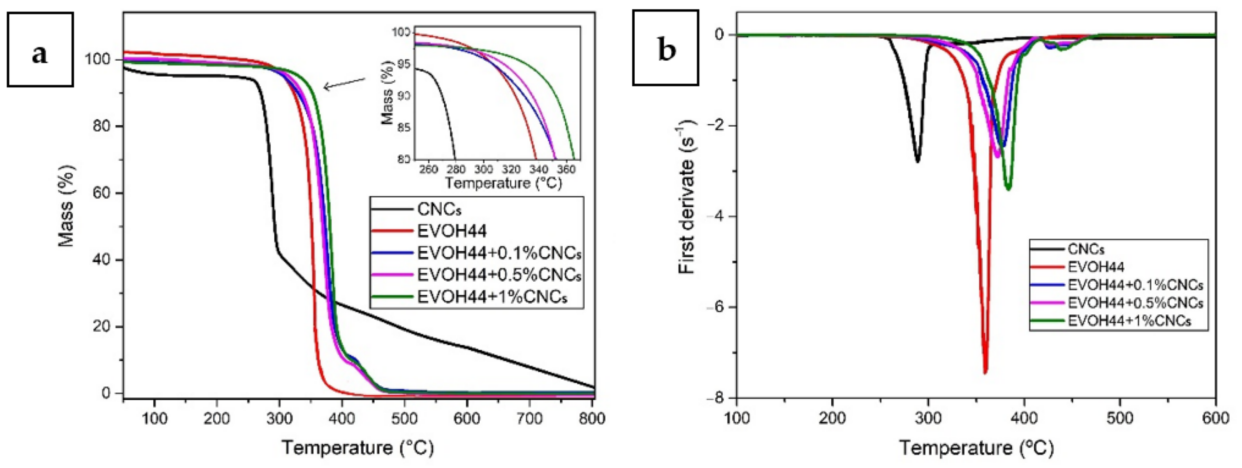

Figure 10. (a) Thermogravimetric (TGA) and (b) first derivative (DTG) curves of the cellulose nanocrystals (CNCs) and of the annealed electrospun films of poly(ethylene-co-vinyl alcohol) with $44 \mathrm{~mol} \%$ of ethylene $\left(\mathrm{EVOH}_{44}\right)$ with and without CNCs. 
Table 4. Thermogravimetric analysis (TGA) main parameters of the annealed electrospun films of poly(ethylene-co-vinyl alcohol) with $44 \mathrm{~mol} \%$ of ethylene $\left(\mathrm{EVOH}_{44}\right)$ with and without cellulose nanocrystals (CNCs) in terms of: onset temperature of degradation $\left(\mathrm{T}_{5} \%\right.$, degradation temperature $\left(\mathrm{T}_{\mathrm{deg}}\right)$, mass loss at $\mathrm{T}_{\mathrm{deg}}$, and residual mass at $800{ }^{\circ} \mathrm{C}$.

\begin{tabular}{|c|c|c|c|c|}
\hline Sample & $\mathrm{T}_{5 \%}\left({ }^{\circ} \mathrm{C}\right)$ & $\mathrm{T}_{\text {deg }}\left({ }^{\circ} \mathrm{C}\right)$ & Mass Loss at $\mathrm{T}_{\mathrm{deg}}(\%)$ & Residual Mass (\%) \\
\hline CNCs & $215.6 \pm 0.4^{\mathrm{a}}$ & $288.9 \pm 0.5^{\mathrm{a}}$ & $41.3 \pm 0.2^{a}$ & $5.8 \pm 0.8^{a}$ \\
\hline $\mathrm{EVOH}_{44}$ & $306.8 \pm 0.9^{b}$ & $359.7 \pm 0.7^{b}$ & $48.5 \pm 0.3^{b}$ & $0.1 \pm 0.1^{\mathrm{b}}$ \\
\hline $\mathrm{EVOH}_{44}+0.1$ wt $\% \mathrm{CNCs}$ & $306.9 \pm 0.7^{\mathrm{b}}$ & $377.4 \pm 1.4^{\mathrm{c}}$ & $60.0 \pm 0.5^{\mathrm{c}}$ & $0.1 \pm 0.1^{b}$ \\
\hline $\mathrm{EVOH}_{44}+0.5 \mathrm{wt} \% \mathrm{CNCs}$ & $314.9 \pm 1.5^{\mathrm{c}}$ & $372.6 \pm 1.1^{\mathrm{d}}$ & $59.6 \pm 0.8^{c}$ & $0.1 \pm 0.1^{b}$ \\
\hline $\mathrm{EVOH}_{44}+1.0 \mathrm{wt} \% \mathrm{CNCs}$ & $331.2 \pm 0.3^{\mathrm{d}}$ & $383.6 \pm 1.4^{\mathrm{e}}$ & $59.7 \pm 0.4^{\mathrm{c}}$ & $0.1 \pm 0.1^{\mathrm{b}}$ \\
\hline
\end{tabular}

${ }^{a-d}$ Different letters in the same column mean significant difference among the samples $(p<0.05)$.

In Figure 10 and Table 4 it can be seen that the electrospun neat $\mathrm{EVOH}_{44}$ film showed a $\mathrm{T}_{5 \%}$ and a $\mathrm{T}_{\text {deg }}$ at $306.8{ }^{\circ} \mathrm{C}$ and $359.7^{\circ} \mathrm{C}$, respectively, with a mass loss of $48.5 \%$ and a residual mass of $0.1 \%$. These results are consistent with other values reported in the literature. For instance, a bar-coated film of poly(ethylene-co-vinyl alcohol) with $32 \mathrm{~mol} \%$ of ethylene $\left(\mathrm{EVOH}_{32}\right)$ film showed a $\mathrm{T}_{\text {deg }}$ at $349.1^{\circ} \mathrm{C}$ [92]. In another study, a solventcasted $\mathrm{EVOH}_{32}$ film presented a $\mathrm{T}_{5 \%}$ and a $\mathrm{T}_{\text {deg }}$ at $270.5^{\circ} \mathrm{C}$ and $381.0^{\circ} \mathrm{C}$, respectively, and a residual mass of $2.2 \%$ [32]. The addition of CNCs improved the thermal stability of $\mathrm{EVOH}_{44}$ since a clear increase in both $\mathrm{T}_{5 \%}$ and a $\mathrm{T}_{\operatorname{deg}}$ was observed, particularly for contents above $0.5 \mathrm{wt} \%$. Thus, the $\mathrm{T}_{5} \%$ increased to $314.9{ }^{\circ} \mathrm{C}$ and $331.2{ }^{\circ} \mathrm{C}$, for the $\mathrm{EVOH}_{44}$ films with a $0.5 \mathrm{wt} \%$ and $1 \mathrm{wt} \% \mathrm{CNCs}$, respectively. The $\mathrm{T}_{\mathrm{deg}}$ values also increased, being located at $377.4,372.6$, and $383.6{ }^{\circ} \mathrm{C}$, for the film samples with $0.1,0.5$, and $1.0 \mathrm{wt} \%$ CNCs, respectively. Finally, all the nanocomposite films presented a mass loss at $T_{\text {deg }}$ of approximately $60 \%$ and a residual mass of $0.1 \%$. Therefore, CNCs successfully delayed the thermal degradation of $\mathrm{EVOH}_{44}$. Furthermore, the nanofillers also benefited from $\mathrm{EVOH}_{44}$ since they seemed to be better stabilized in the copolymer matrix. This phenomenon has been previously reported by Orr et al. [93], who prepared and characterized $\mathrm{EVOH}_{48}$ films with CNCs by the solution casting method. Also, Noorani et al. [94] reported an increase in thermal stability when $\mathrm{CNCs}$ was added to a polysulfone resin by a solvent exchange process, indicating not only good CNCs dispersion, but also a good interfacial interaction with the polymer matrix.

\subsection{ATR-FTIR Spectroscopy of the Annealed Electrospun Films}

Figure 11 displays the FTIR spectra of the CNC powder and of the various electrospun $\mathrm{EVOH}_{44}$ mats loaded with CNCs. For the CNCs powder, the strong and broad absorption peak at $3326 \mathrm{~cm}^{-1}$ was ascribed to the $-\mathrm{OH}$ stretching vibration of the sample with a contribution from any sorbed water [95]. Assignments can also be made for the peak at $2900 \mathrm{~cm}^{-1}$ (CH stretching vibrations), 1054, and $898 \mathrm{~cm}^{-1}$ (C-O stretching) [96-98]. The band at $1640 \mathrm{~cm}^{-1}$ was also associated with the sorbed water [97]. Furthermore, the peaks at 1612 and $1429 \mathrm{~cm}^{-1}$ were assigned to asymmetric and symmetric stretching vibrations of $-\mathrm{COOH}$ [99]. Finally, the $667 \mathrm{~cm}^{-1}$ peak was attributed to the $\mathrm{C}-\mathrm{OH}$ out-of-plane bending mode [100]. There was no indication of remaining lignin in the CNCs since the lignin contribution has characteristic peaks around $1500 \mathrm{~cm}^{-1}$ [101].

Upon the addition of CNCs to the pure $\mathrm{EVOH}_{44}$, there was no evidence of any new peaks or changes in the position of the characteristic $\mathrm{EVOH}_{44}$ peaks. This result suggests that, for the loadings used, there was no detectable interaction that could be picked up by the technique between $\mathrm{EVOH}_{44}$ and $\mathrm{CNCs}$, which are both known to be strongly selfassociated polymers. These finding are in accordance with those reported elsewhere in the literature for other similar systems. For example, in an $\mathrm{EVOH}_{32}$ film with $\mathrm{BCNWs}$, the cellulose characteristic bands were not observed up to concentrations of $3 \mathrm{wt} \% \mathrm{BCNWs}$ [77]. In another study, an $\mathrm{EVOH}_{32}$ film with $1.0 \mathrm{wt} \% \mathrm{CNCs}$ was also no loaded enough to show unambiguous changes in the spectra [32]. 


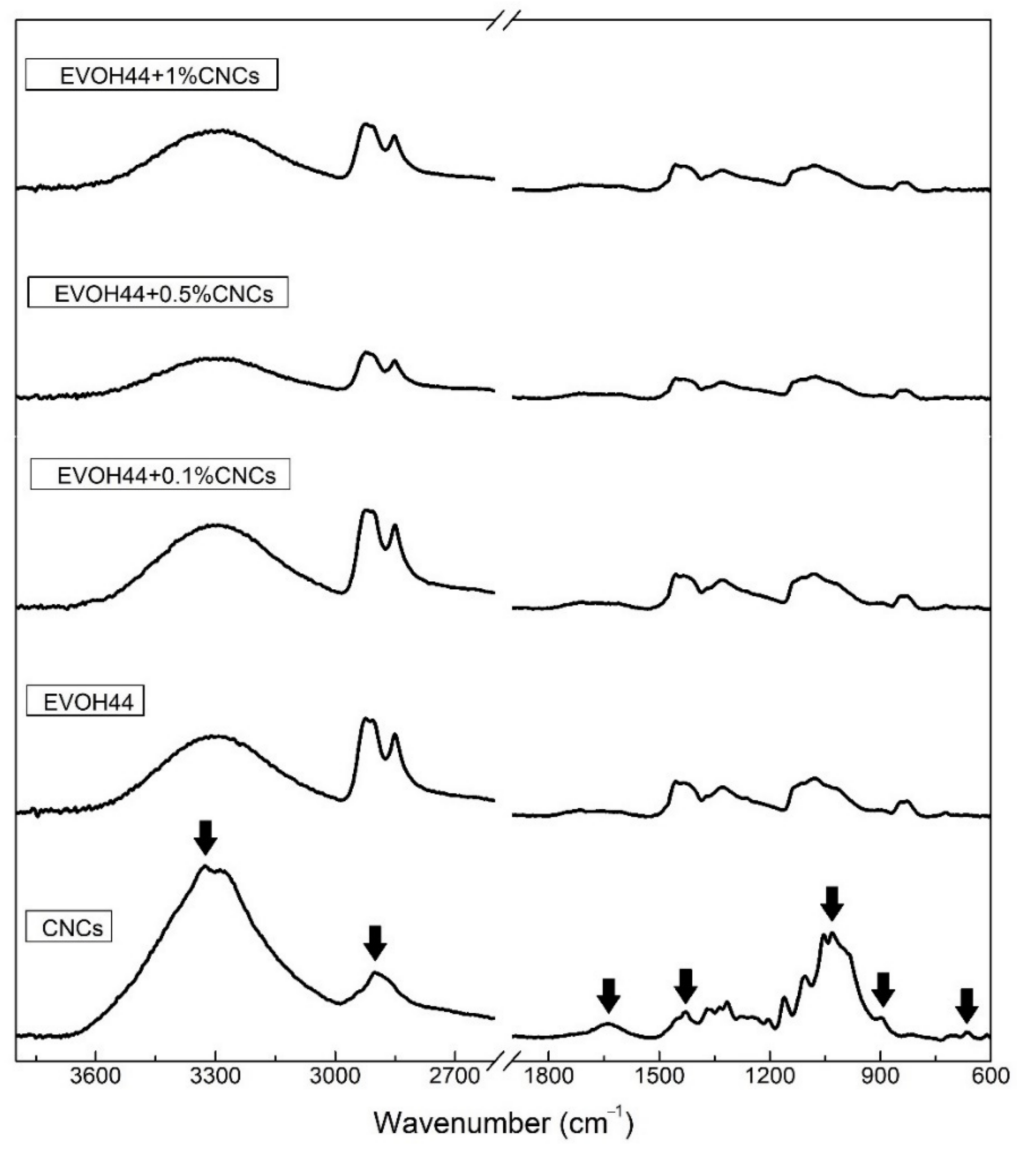

Figure 11. Fourier transform infrared spectroscopy (FTIR) spectra of the cellulose nanocrystals (CNCs) powder and of the annealed electrospun films of poly(ethylene-co-vinyl alcohol) with $44 \mathrm{~mol} \%$ of ethylene $\left(\mathrm{EVOH}_{44}\right)$ with and without CNCs. The arrows refer to the bands discussed in the text.

\subsection{Mechanical Properties of the Annealed Electrospun Films}

Table 5 gathers the values of the elastic modulus $(\mathrm{E})$, tensile strength at break $\left(\sigma_{\mathrm{b}}\right)$, elongation at break $\left(\varepsilon_{\mathrm{b}}\right)$, and toughness $(\mathrm{T})$ of the electrospun $\mathrm{EVOH}_{44}$ films calculated from their strain-stress curves obtained at room temperature and shown in Figure 12. The neat $\mathrm{EVOH}_{44}$ film showed values of $\mathrm{E}$ of $4699 \mathrm{MPa}, \sigma_{\mathrm{y}}$ of $38.7 \mathrm{MPa}, \varepsilon_{\mathrm{b}}$ of $10.4 \%$, and $\mathrm{T}$ of $3.2 \mathrm{~mJ} / \mathrm{m}^{3}$. When CNCs were incorporated into $\mathrm{EVOH}_{44}$, the $\mathrm{E}$ values increased for contents of 0.1 and $0.5 \mathrm{wt} \%$, by $37.75 \%$ and $28.15 \%$, respectively, while $\sigma_{\mathrm{y}}$ was kept in the 30-40 MPa range, hence resulting in more rigid films. However, the mechanical strength decreased at the CNC loading of $1.0 \mathrm{wt} \%$, showing values of $E$ and $\sigma_{\mathrm{y}}$ of 4135 and 25.2 $\mathrm{MPa}$, respectively. Moreover, the ductility of the electrospun $\mathrm{EVOH}_{44}$ films decreased significantly for all the CNC contents, showing values of $\varepsilon_{\mathrm{b}}$ and $\mathrm{T}$ in the ranges of $0.7-1.6 \%$ and a $\mathrm{T}$ of $0.2-0.3 \mathrm{~mJ} / \mathrm{m}^{3}$.

Table 5. Mechanical properties of the annealed electrospun films of poly(ethylene-co-vinyl alcohol) with $44 \mathrm{~mol} \%$ of ethylene $\left(\mathrm{EVOH}_{44}\right)$ with and without cellulose nanocrystals $(\mathrm{CNCs})$ in terms of: tensile modulus $(\mathrm{E})$, tensile strength at yield $\left(\sigma_{\mathrm{y}}\right)$, elongation at break $\left(\varepsilon_{\mathrm{b}}\right)$, and toughness $(\mathrm{T})$.

\begin{tabular}{ccccc}
\hline Film & $\boldsymbol{E}$ & $\sigma_{\boldsymbol{y}} \mathbf{( M P a )}$ & $\varepsilon_{\boldsymbol{b}} \mathbf{( \% )}$ & $\mathbf{T}\left(\mathbf{m} \mathbf{m} / \mathbf{m}^{\mathbf{3}}\right)$ \\
\hline $\mathrm{EVOH}_{44}$ & $4699 \pm 350^{\mathrm{a}}$ & $38.7 \pm 5.2^{\mathrm{a}}$ & $10.4 \pm 3.6^{\mathrm{a}}$ & $3.2 \pm 1.4^{\mathrm{a}}$ \\
$\mathrm{EVOH}_{44}+0.1 \mathrm{wt} \% \mathrm{CNCs}$ & $6473 \pm 257^{\mathrm{b}}$ & $39.2 \pm 8.6^{\mathrm{a}, \mathrm{b}}$ & $0.8 \pm 0.5^{\mathrm{b}}$ & $0.2 \pm 0.1^{\mathrm{b}}$ \\
$\mathrm{EVOH}_{44}+0.5 \mathrm{wt} \% \mathrm{CNCs}$ & $6022 \pm 584^{\mathrm{b}}$ & $30.2 \pm 8.3^{\mathrm{a}, \mathrm{b}}$ & $0.7 \pm 0.2^{\mathrm{b}}$ & $0.2 \pm 0.1^{\mathrm{b}}$ \\
EVOH $_{44}+1.0 \mathrm{wt} \% \mathrm{CNCs}$ & $4135 \pm 399^{\mathrm{a}}$ & $25.2 \pm 7.7^{\mathrm{b}}$ & $1.6 \pm 0.7^{\mathrm{b}}$ & $0.3 \pm 0.1^{\mathrm{b}}$ \\
\hline
\end{tabular}

$\overline{\mathrm{a}, \mathrm{b}}$ Different letters in the same column mean significant difference among the samples $(p<0.05)$. 


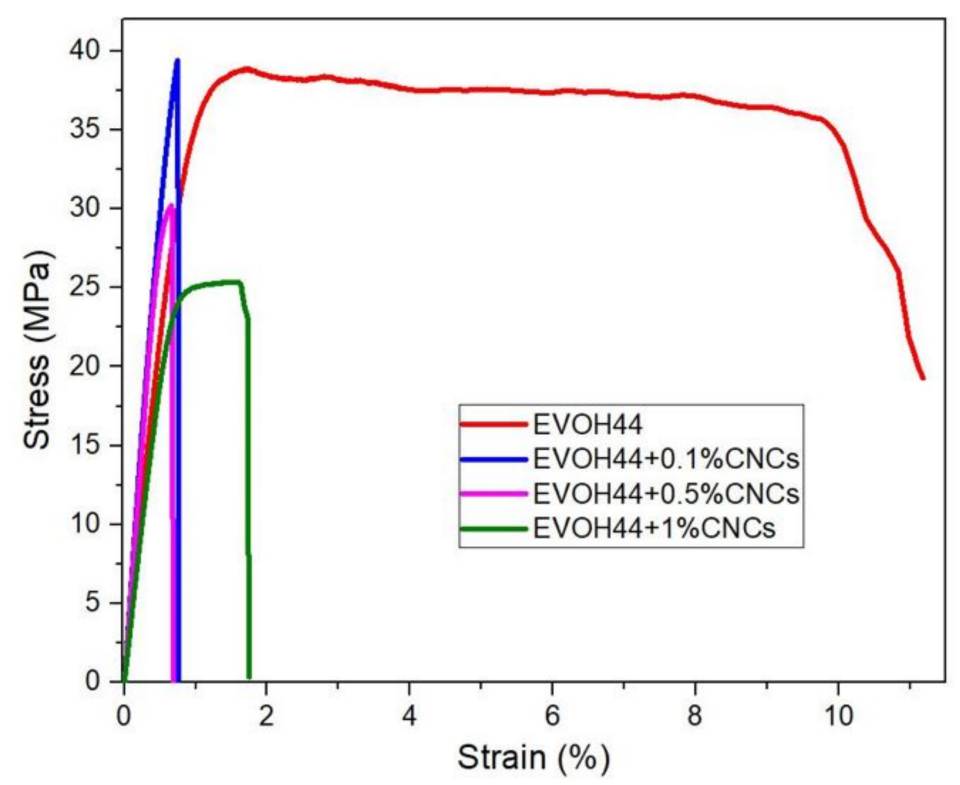

Figure 12. Tensile stress-strain curves of the annealed electrospun films of poly(ethylene-co-vinyl alcohol) with $44 \mathrm{~mol} \%$ of ethylene $\left(\mathrm{EVOH}_{44}\right)$ with and without cellulose nanocrystals (CNCs).

Previous works dealing with polymer nanocomposites based on CNCs have reported a similar mechanical behavior. For instance, $\mathrm{EVOH}_{32} /$ cellulose nanowhisker (CNW) nanocomposites prepared by melt compounding showed an increase in tensile modulus and tensile strength but accompanied with a decrease in ductility when increasing the nanofiller content, producing stronger but more brittle materials [102]. Also, polylactide acid (PLA) nanocomposite fibers containing 1-3 wt \% BCNWs prepared by electrospinning and, then, melt-mixed with PLA pellets by melt compounding showed a percentage increase in Young's modulus and tensile strength of about $15 \%$, but a decrease in $\varepsilon_{b}$ of $10 \%$ [103]. In another study, PLA/MFC nanocomposites prepared by solvent mixing and, then, hot-pressed into sheets, also presented an increase in both tensile modulus and tensile strength, but a decrease in strain at break [104]. Similarly, functionalized cellulose nanocrystal methyl ester (CNC-me) incorporated into PHBV films prepared by solution casting showed an increase in Young's modulus and tensile strength of $250 \%$ and $147 \%$, respectively, when increasing the CNC content, while $\varepsilon_{b}$ considerably decreased [105]. A similar effect was observed for PVOH films reinforced with CNCs also prepared by solvent casting [106,107]. Different factors have been hypothesized to influence the mechanical properties of polymers reinforced with CNCs. Thus, in addition to potential interactions between the polymer matrix and cellulosic nanofillers in the amorphous phase, the dispersion and distribution of the CNCs in the matrix has a significant effect [105]. In particular, it has been described that an increase in mechanical strength is due to a good stress transfer across the interphase due to the interfacial bond that occurs between the CNCs and the polymer matrix $[108,109]$. Moreover, achieving the percolation threshold is critical for obtaining an enhanced mechanical performance. This consists on the formation of a 3-dimensional (3D) nanocrystal network via hydrogen bonding forces that connect the fillers throughout the polymer matrix. This phenomenon can be affected by different parameters, such as particle interactions, orientation, or aspect ratio [110]. With CNCs, it has been described that a good dispersion of the nanocrystals, without agglomerations, can favor the elimination of the defects or stress concentrators [39]. Therefore, even though, the FTIR analysis did not resolve any potential hydrogen bonding interactions between the components, it is clear that the electrospun $\mathrm{EVOH}_{44}$ films having $0.1 \mathrm{wt} \% \mathrm{CNCs}$, with best reported filler distribution, showed an optimal balance in mechanical properties. On the contrary, the sample with $1.0 \mathrm{wt} \% \mathrm{CNCs}$, which showed more agglomerations, presented a reduction in the reinforcement of the copolymer matrix. 


\subsection{Barrier Properties of the Annealed Electrospun Films}

The WVP and OP values of the annealed electrospun $\mathrm{EVOH}_{44}$ films, with and without CNCs, are shown in Table 6. The neat $\mathrm{EVOH}_{44}$ film showed the highest barrier performance, that is, the lowest permeabilities. Thus, for $\mathrm{WVP} \mathrm{EVOH}_{44}$ film showed a value of $1.6 \times 10^{-14} \mathrm{~kg} \cdot \mathrm{m} \cdot \mathrm{m}^{-2} \cdot \mathrm{Pa}^{-1} \cdot \mathrm{s}^{-1}$. OP was measured at different $\% \mathrm{RH}$, namely $0 \%, 20 \%$, and $80 \%$, in order to assess the effect of humidity on the oxygen permeability. From Figure 13, which plots the evolution of the oxygen barrier as function of \% RH, it can be observed that the $\mathrm{EVOH}_{44}$ film presented good oxygen barrier at low humidity, showing values of $1.1 \times 10^{-20}$ and $0.1 \times 10^{-20} \mathrm{~m}^{3} \cdot \mathrm{m} \cdot \mathrm{m}^{-2} \cdot \mathrm{Pa}^{-1} \cdot \mathrm{s}^{-1}$ for $0 \%$ and $20 \% \mathrm{RH}$, respectively. However, at the highest humidity, that is, $80 \%$, the barrier decreased to $4.7 \times 10^{-20} \mathrm{~m}^{3} \cdot \mathrm{m} \cdot \mathrm{m}^{-2} \cdot \mathrm{Pa}^{-1} \cdot \mathrm{s}^{-1}$. In hydrophilic polymers, which is the case of the EVOH copolymers, it has been reported an increase in the permeability to oxygen gas due to water-induced plasticization at high humidity [111]. In this plasticization regime, sorbed water molecules intercept the strong polymer interchain self-association, leading to water molecules clustering, and hence to an increase in free volume that allow the gas molecules to diffuse through [89]. It is also known that at lower humidity, the sorbed water is not able to break the strong interchain hydrogen bonding, hence the water molecules block the existing free volume instead, thus reducing the available sites for diffusion [111].

Table 6. Values of water vapor permeability (WVP), and oxygen permeability (OP) of the annealed electrospun films of poly(ethylene-co-vinyl alcohol) with $44 \mathrm{~mol} \%$ of ethylene $\left(\mathrm{EVOH}_{44}\right)$ with and without cellulose nanocrystals (CNCs).

\begin{tabular}{|c|c|c|c|c|}
\hline \multirow{2}{*}{ Film } & \multirow{2}{*}{$\begin{array}{c}\text { WVP } \times 10^{14} \\
\left(\mathrm{~kg} \cdot \mathrm{m} \cdot \mathrm{m}^{-2} \cdot \mathrm{Pa}^{-1} \cdot \mathrm{s}^{-1}\right)\end{array}$} & \multicolumn{3}{|c|}{$\mathrm{OP} \times 10^{20}\left(\mathrm{~m}^{3} \cdot \mathrm{m} \cdot \mathrm{m}^{-2} \cdot \mathrm{Pa}^{-1} \cdot \mathrm{s}^{-1}\right)$} \\
\hline & & 0\% RH & $20 \% \mathrm{RH}$ & $80 \% \mathrm{RH}$ \\
\hline $\mathrm{EVOH}_{44}$ & $1.6 \pm 0.4^{\mathrm{a}}$ & $1.1 \pm 0.2^{\mathrm{a}}$ & $0.10 \pm 0.04^{\mathrm{a}}$ & $4.7 \pm 0.3^{a}$ \\
\hline $\mathrm{EVOH}_{44}+0.1 \mathrm{wt} \% \mathrm{CNCs}$ & $3.7 \pm 0.3^{b}$ & $1.4 \pm 0.1^{\mathrm{a}}$ & $0.38 \pm 0.01^{b}$ & $8.3 \pm 0.2^{b}$ \\
\hline $\mathrm{EVOH}_{44}+0.5 \mathrm{wt} \% \mathrm{CNCs}$ & $4.1 \pm 0.9^{b, c}$ & $2.7 \pm 0.2^{b}$ & $0.53 \pm 0.03 \mathrm{~b}, \mathrm{c}$ & $8.8 \pm 0.2^{b}$ \\
\hline $\mathrm{EVOH}_{44}+1.0 \mathrm{wt} \% \mathrm{CNCs}$ & $4.5 \pm 0.1^{\mathrm{c}}$ & $2.3 \pm 0.4^{b}$ & $0.61 \pm 0.01^{\mathrm{c}}$ & $8.7 \pm 0.2^{b}$ \\
\hline
\end{tabular}

$\overline{\mathrm{a}-\mathrm{c}}$ Different letters in the same column mean significant difference among the samples $(p<0.05)$.

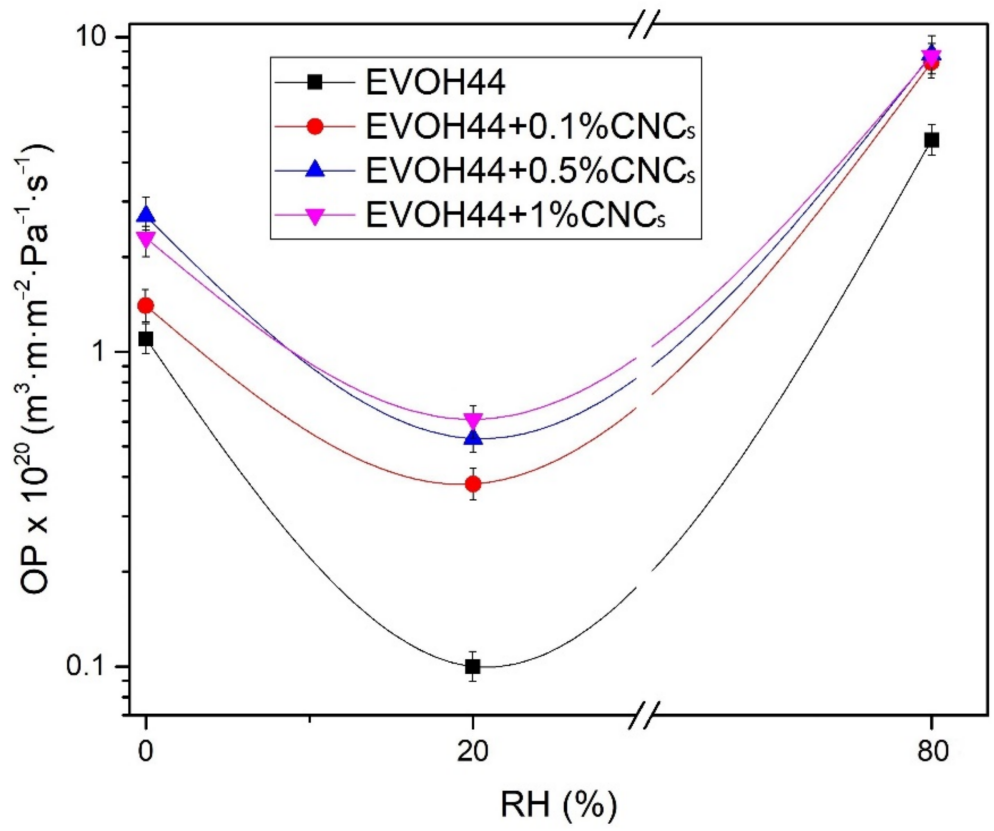

Figure 13. Evolution of oxygen permeability (OP) in log scale as a function of the percentage of relative humidity (\% $\mathrm{RH}$ ) of the annealed electrospun films of poly(ethylene-co-vinyl alcohol) with $44 \mathrm{~mol} \%$ of ethylene $\left(\mathrm{EVOH}_{44}\right)$ with and without cellulose nanocrystals (CNCs). 
Compared to other $\mathrm{EVOH}_{44}$ films studied in the literature, the values reported herein for the $\mathrm{EVOH}_{44}$ films are within the same order of magnitude. For instance, $\mathrm{EVOH}_{44}$ films prepared by extrusion showed a WVP of $0.25 \times 10^{-14} \mathrm{~kg} \cdot \mathrm{m} \cdot \mathrm{m}^{-2} \cdot \mathrm{Pa}^{-1} \cdot \mathrm{s}^{-1}$ [103], whereas for others prepared by solvent casting it was $0.11 \times 10^{-14} \mathrm{~kg} \cdot \mathrm{m} \cdot \mathrm{m}^{-2} \cdot \mathrm{Pa}^{-1} \cdot \mathrm{s}^{-1}$ [84]. In terms of oxygen barrier, an OP value of $0.77 \times 10^{-21} \mathrm{~m} \cdot \mathrm{m} \cdot \mathrm{m}^{-2} \cdot \mathrm{Pa}^{-1} \cdot \mathrm{s}^{-1}$ was reported for $\mathrm{EVOH}_{32}$ in dry conditions, while a value of $9.1 \times 10^{-20} \mathrm{~m} \cdot \mathrm{m} \cdot \mathrm{m}^{-2} \cdot \mathrm{Pa}^{-1} \cdot \mathrm{s}^{-1}$ was obtained in wet conditions [112]. The OP of a solvent-cast $\mathrm{EVOH}_{44}$ film was studied at different $\% \mathrm{RH}$, resulting in values of $0.42 \times 10^{-20} \mathrm{~m}^{3} \cdot \mathrm{m} \cdot \mathrm{m}^{-2} \cdot \mathrm{Pa}^{-1} \cdot \mathrm{s}^{-1}$ at $65 \% \mathrm{RH}$ and $0.26 \times 10^{-20} \mathrm{~m}^{3} \cdot \mathrm{m} \cdot \mathrm{m}^{-2} \cdot \mathrm{Pa}^{-1} \cdot \mathrm{s}^{-1}$ at $0 \% \mathrm{RH}$ [113]. Also, the OP of a melt-extruded $\mathrm{EVOH}_{44}$ film was measured at different $\% \mathrm{RH}$, with values of $9 \times 10^{-20} \mathrm{~m} \cdot \mathrm{m} \cdot \mathrm{m}^{-2} \cdot \mathrm{Pa}^{-1} \cdot \mathrm{s}^{-1}$ at $50 \%$ $\mathrm{RH}$ and $9 \times 10^{-19} \mathrm{~m}^{3} \cdot \mathrm{m} \cdot \mathrm{m}^{-2} \cdot \mathrm{Pa}^{-1} \cdot \mathrm{s}^{-1}$ at $90 \% \mathrm{RH}$. These results indicate that the barrier properties of the annealed electrospun fiber-based $\mathrm{EVOH}_{44}$ films obtained are somewhat lower, but within the same order of magnitude, than films of this copolymer processed by other techniques.

When CNCs were incorporated into the electrospun $\mathrm{EVOH}_{44}$ fibers, an increase in permeability was observed in the resulting films. In general terms, the films with different CNC contents showed minor differences between them, in most cases being not significant, though there was a tendency for the barrier properties to decrease with increasing the nanofiller content. Finally, the OP values were also determined at the three \% RH tested, exhibiting a similar trend as for the case of the $\mathrm{EVOH}_{44}$ film. Therefore, the best barrier performance for oxygen was also found at $20 \% \mathrm{RH}$. However, the effect of the CNC loading at this \% RH was also the most significant, which points out that the hydrophilic and rigid nature of the CNCs and the lower crystallinity of the copolymer matrix, increased the free volume, thus facilitating gas diffusion.

Although, in general nanocelluloses, when used as fillers, have been reported to improve the gas barrier properties of polymers [114,115], the fact that the polymer used in this study is already a very high-gas-barrier material explains the reduction observed [116]. Syverud et al. [117] reported OP values of $4.3-5.8 \times 10^{-20} \mathrm{~m}^{3} \cdot \mathrm{m} \cdot \mathrm{m}^{-2} \cdot \mathrm{Pa}^{-1} \cdot \mathrm{s}^{-1}$ for MFC films, whereas Nair et al. [118] reported OP values of $6.9 \times 10^{-21}$ and $0.1-1.2 \times 10^{-21} \mathrm{~m}^{3} \cdot \mathrm{m} \cdot \mathrm{m}^{-2} \cdot \mathrm{Pa}^{-1} \cdot \mathrm{s}^{-1}$ for CNCs and EVOH films, respectively. In addition, it should be noted that the introduction of the $\mathrm{CNCs}$ in the experiments reported here was found to lead to a lower crystallinity for the copolymer, factor that is known to reduce permeability by increasing free volume and reducing tortuosity $[119,120]$. Similar observations have been previously reported after addition of MFC to EVOH, which led to a decrease in WVP due to changes in morphology and crystallinity [84]. The same observation was also found by Petersson et al. [121], who showed a reduction in OP when microcrystalline cellulose (MCC) was added to PLA due to a decrease in the degree of crystallinity.

\section{Conclusions}

The present study demonstrated the potential of the electrospinning process to obtain a new high-gas-barrier transparent fiber-based $\mathrm{EVOH}_{44}$ film. This material shows barrier properties somewhat lower than those of the same copolymer processed by other conventional processing technologies. The incorporation of CNCs increased the thermal and mechanical resistance of the fiber-based $\mathrm{EVOH}_{44}$ film, unfortunately for contents not exciding of $0.5 \mathrm{wt} \%$, and exhibiting optimal balanced properties at $0.1 \mathrm{wt} \%$. In this case, hybrid bio-/non-bio nanocomposites can be obtained with enhanced rigidity but reduced flexibility and slightly lower barrier properties. Still these hybrid nanocomposites offer the advantage of remaining in the high-barrier regime. The lower annealing temperature required for the $\mathrm{EVOH}_{44}$ copolymer and its nanocomposites with $\mathrm{CNCs}$, enable them to be used as barrier interlayers, compatible with many more polymers and biopolymers than their higher vinyl-alcohol content homologous copolymers. Future work will deal with the application of these novel barrier materials as very thin interlayers in compostable multilayer systems, to ascertain the overall barrier reinforcement and physicochemical properties, and also their biodegradability under industrial and home composting conditions. 
Author Contributions: Conceptualization, J.M.L.; Methodology, development and characterization, B.M.-R., Investigation and development, L.Z.; FT-IR analysis, C.S.; Mechanical properties, L.C.; Writing-original draft preparation, B.M.-R.; Writing-review and editing, S.T.-G. and C.P.; Supervision, S.T.-G., C.P. and J.M.L.; Project Administration, J.M.L. All authors have read and agreed to the published version of the manuscript.

Funding: This research work was funded by the EU H2020 BBI JU project USABLE PAKAGING (reference number 836884) and by the Spanish Ministry of Science and Innovation (MICI) project RTI2018-097249-B-C21.

Acknowledgments: B.M.-R. would like to acknowledge the MICI for her FPI fellowship (BES-2016077972) and S.T.-G. for his MICI Juan de la Cierva-Incorporación contract (IJCI-2016-29675). The authors would also like to thank the Unidad Asociada IATA(CSIC)-UJI in "Plastics Technology".

Conflicts of Interest: The authors declare no conflict of interest.

\section{References}

1. Torres-Giner, S.; Gil, L.; Pascual-Ramírez, L.; Garde-Belza, J.A. Packaging: Food Waste Reduction. In Encyclopedia of Polymer Applications; CRC Press: Boca Raton, FL, USA, 2019.

2. Sidwell, J.A. Food Contact Polymeric Materials; Rapra Technology: Akron, OH, USA, 1992.

3. Marie, E.; Chevalier, Y.; Issartel, N.; Eydoux, F.; Germanaud, L.; Flores, P. The Controlled Solvolysis of Ethylene-Vinyl Acetate Copolymers. Macromolecules 2001, 34, 5838-5847. [CrossRef]

4. Mokwena, K.K.; Tang, J.; Dunne, C.P.; Yang, T.C.S.; Chow, E. Oxygen transmission of multilayer EVOH films after microwave sterilization. J. Food Eng. 2009, 92, 291-296. [CrossRef]

5. Katayama, T. New development of ethylene-vinyl alcohol copolymer fiber. Kinoshi Kenkyu Kaishi Ann. High Perform. Pap. Soc. Jpn. 2005, 44, 43-48.

6. Yokoyama, Y.; Kimata, H.; Mitarai, S.; Hirano, S.; Shirakawa, T. Ethylene vinyl alcohol (EVOH) fiber compared to cotton underwear in the treatment of childhood atopic dermatitis: A double-blind randomized study. Indian Pediatr. 2009, 46, 611-614.

7. Luzi, F.; Torre, L.; Puglia, D. Antioxidant Packaging Films Based on Ethylene Vinyl Alcohol Copolymer (EVOH) and Caffeic Acid. Molecules 2020, 25, 3953. [CrossRef]

8. Gavara, R.; Catalá, R.; López Carballo, G.; Cerisuelo, J.P.; Dominguez, I.; Muriel-Galet, V.; Hernandez-Muñoz, P. Use of EVOH for Food Packaging Applications. In Reference Module in Food Science; Elsevier: Amsterdam, The Netherlands, 2016.

9. Arboleda, C.E.; Mejía, A.I.G.; López, B.L.O. Poly (vinylalcohol-co-ethylene) biodegradation on semi solid fermentation by Phanerochaete chrysosporium. Acta Farm. Bonaer. 2004, 23, 123-128.

10. Mejía, A.I.G.; López, B.L.O.; Sierra, L. Biodegradation of poly(vinylalcohol-co-ethylene) with the fungus phanerochaete chrysosporium. Mater. Res. Innov. 2001, 4, 148-154. [CrossRef]

11. Erlandsson, B.; Karlsson, S.; Albertsson, A. Biodegradation of C-14 labeled poly (ethylene-co-vinyl alcohol). In Abstracts of Papers of the American Chemical Society; American Chemical Society: Washington, DC, USA, 1997.

12. Tomita, K.; Kojoh, K.; Suzuki, A. Isolation of thermophiles assimilating poly(ethylene-co-vinyl alcohol). J. Ferment. Bioeng. 1997, 84, 400-402. [CrossRef]

13. Cerrada, M.L.; Pérez, E.; Pereña, J.M.; Benavente, R. Wide-Angle X-ray Diffraction Study of the Phase Behavior of Vinyl Alcohol-Ethylene Copolymers. Macromolecules 1998, 31, 2559-2564. [CrossRef]

14. Mokwena, K.K.; Tang, J. Ethylene Vinyl Alcohol: A Review of Barrier Properties for Packaging Shelf Stable Foods. Crit. Rev. Food Sci. Nutr. 2012, 52, 640-650. [CrossRef]

15. Ito, K.; Saito, Y.; Yamamoto, T.; Ujihira, Y.; Nomura, K. Correlation Study between Oxygen Permeability and Free Volume of Ethylene-Vinyl Alcohol Copolymer through Positronium Lifetime Measurement. Macromolecules 2001, 34, 6153-6155. [CrossRef]

16. Tajeddin, B. Cellulose-Based Polymers for Packaging Applications. In Lignocellulosic Polymer Composites; Scrivener Publishing LLC.: Beverly, MA, USA, 2014; pp. 477-498.

17. De Souza Lima, M.M.; Borsali, R. Rodlike Cellulose Microcrystals: Structure, Properties, and Applications. Macromol. Rapid Commun. 2004, 25, 771-787. [CrossRef]

18. García, A.; Gandini, A.; Labidi, J.; Belgacem, N.; Bras, J. Industrial and crop wastes: A new source for nanocellulose biorefinery. Ind. Crop. Prod. 2016, 93, 26-38. [CrossRef]

19. Raquez, J.-M.; Habibi, Y.; Murariu, M.; Dubois, P. Polylactide (PLA)-based nanocomposites. Prog. Polym. Sci. 2013, 38, 1504-1542. [CrossRef]

20. Henriksson, M.; Henriksson, G.; Berglund, L.A.; Lindström, T. An environmentally friendly method for enzyme-assisted preparation of microfibrillated cellulose (MFC) nanofibers. Eur. Polym. J. 2007, 43, 3434-3441. [CrossRef]

21. Fortunati, E.; Armentano, I.; Zhou, Q.; Iannoni, A.; Saino, E.; Visai, L.; Berglund, L.A.; Kenny, J.M. Multifunctional bionanocomposite films of poly(lactic acid), cellulose nanocrystals and silver nanoparticles. Carbohydr. Polym. 2012, 87, 1596-1605. [CrossRef]

22. Gatenholm, P.; Klemm, D. Bacterial nanocellulose as a renewable material for biomedical applications. MRS Bull. 2010, 35, 208-213. [CrossRef] 
23. Mariano, M.; El Kissi, N.; Dufresne, A. Cellulose nanocrystals and related nanocomposites: Review of some properties and challenges. J. Polym. Sci. Part B Polym. Phys. 2014, 52, 791-806. [CrossRef]

24. Ashori, A.; Jonoobi, M.; Ayrilmis, N.; Shahreki, A.; Fashapoyeh, M.A. Preparation and characterization of polyhydroxybutyrateco-valerate (PHBV) as green composites using nano reinforcements. Int. J. Biol. Macromol. 2019, 136, 1119-1124. [CrossRef]

25. Voronova, M.I.; Surov, O.V.; Guseinov, S.S.; Barannikov, V.P.; Zakharov, A.G. Thermal stability of polyvinyl alcohol/nanocrystalline cellulose composites. Carbohydr. Polym. 2015, 130, 440-447. [CrossRef]

26. Perumal, A.B.; Sellamuthu, P.S.; Nambiar, R.B.; Sadiku, E.R. Development of polyvinyl alcohol/chitosan bio-nanocomposite films reinforced with cellulose nanocrystals isolated from rice straw. Appl. Surf. Sci. 2018, 449, 591-602. [CrossRef]

27. Lei, W.; Fang, C.; Zhou, X.; Yin, Q.; Pan, S.; Yang, R.; Liu, D.; Ouyang, Y. Cellulose nanocrystals obtained from office waste paper and their potential application in PET packing materials. Carbohydr. Polym. 2018, 181, 376-385. [CrossRef] [PubMed]

28. Pal, N.; Banerjee, S.; Roy, P.; Pal, K. Reduced graphene oxide and PEG-grafted TEMPO-oxidized cellulose nanocrystal reinforced poly-lactic acid nanocomposite film for biomedical application. Mater. Sci. Eng. C 2019, 104, 109956. [CrossRef] [PubMed]

29. He, Y.; Li, H.; Fei, X.; Peng, L. Carboxymethyl cellulose/cellulose nanocrystals immobilized silver nanoparticles as an effective coating to improve barrier and antibacterial properties of paper for food packaging applications. Carbohydr. Polym. 2021, 252, 117156. [CrossRef] [PubMed]

30. Yang, X.; Zhao, Y.; Mussana, H.; Tessema, M.; Liu, L. Characteristics of cotton fabric modified with chitosan (CS)/cellulose nanocrystal (CNC) nanocomposites. Mater. Lett. 2018, 211, 300-303. [CrossRef]

31. Yu, X.; Tong, S.; Ge, M.; Wu, L.; Zuo, J.; Cao, C.; Song, W. Adsorption of heavy metal ions from aqueous solution by carboxylated cellulose nanocrystals. J. Environ. Sci. 2013, 25, 933-943. [CrossRef]

32. Cherpinski, A.; Biswas, A.; Lagaron, J.M.; Dufresne, A.; Kim, S.; Buttrum, M.; Espinosa, E.; Cheng, H.N. Preparation and evaluation of oxygen scavenging nanocomposite films incorporating cellulose nanocrystals and Pd nanoparticles in poly(ethyleneco-vinyl alcohol). Cellulose 2019, 26, 7237-7251. [CrossRef]

33. Yadav, M.; Liu, Y.-K.; Chiu, F.-C. Fabrication of Cellulose Nanocrystal/Silver/Alginate Bionanocomposite Films with Enhanced Mechanical and Barrier Properties for Food Packaging Application. Nanomaterials 2019, 9, 1523. [CrossRef]

34. Miao, C.; Hamad, W.Y. Cellulose reinforced polymer composites and nanocomposites: A critical review. Cellulose 2013, 20, 2221-2262. [CrossRef]

35. Venkatraman, P.; Gohn, A.M.; Rhoades, A.M.; Foster, E.J. Developing high performance PA 11/cellulose nanocomposites for industrial-scale melt processing. Compos. Part B Eng. 2019, 174, 106988. [CrossRef]

36. Favier, V.; Canova, G.R.; Shrivastava, S.C.; Cavaillé, J.Y. Mechanical percolation in cellulose whisker nanocomposites. Polym. Eng. Sci. 1997, 37, 1732-1739. [CrossRef]

37. Oksman, K.; Aitomäki, Y.; Mathew, A.P.; Siqueira, G.; Zhou, Q.; Butylina, S.; Tanpichai, S.; Zhou, X.; Hooshmand, S. Review of the recent developments in cellulose nanocomposite processing. Compos. Part A Appl. Sci. Manuf. 2016, 83, 2-18. [CrossRef]

38. Khoshkava, V.; Kamal, M.R. Effect of Cellulose Nanocrystals (CNC) Particle Morphology on Dispersion and Rheological and Mechanical Properties of Polypropylene/CNC Nanocomposites. ACS Appl. Mater. Interfaces 2014, 6, 8146-8157. [CrossRef]

39. Cao, Y.; Zavattieri, P.; Youngblood, J.; Moon, R.; Weiss, J. The relationship between cellulose nanocrystal dispersion and strength Constr. Build. Mater. 2016, 119, 71-79. [CrossRef]

40. Gupta, A.; Simmons, W.; Schueneman, G.T.; Hylton, D.; Mintz, E.A. Rheological and Thermo-Mechanical Properties of Poly(lactic acid)/Lignin-Coated Cellulose Nanocrystal Composites. ACS Sustain. Chem. Eng. 2017, 5, 1711-1720. [CrossRef]

41. González, K.; Iturriaga, L.; González, A.; Eceiza, A.; Gabilondo, N. Improving mechanical and barrier properties of thermoplastic starch and polysaccharide nanocrystals nanocomposites. Eur. Polym. J. 2020, 123, 109415. [CrossRef]

42. Arias, A.; Heuzey, M.-C.; Huneault, M.A.; Ausias, G.; Bendahou, A. Enhanced dispersion of cellulose nanocrystals in meltprocessed polylactide-based nanocomposites. Cellulose 2015, 22, 483-498. [CrossRef]

43. Zhang, W.; He, X.; Li, C.; Zhang, X.; Lu, C.; Zhang, X.; Deng, Y. High performance poly (vinyl alcohol)/cellulose nanocrystals nanocomposites manufactured by injection molding. Cellulose 2014, 21, 485-494. [CrossRef]

44. Oksman, K.; Mathew, A.P.; Bondeson, D.; Kvien, I. Manufacturing process of cellulose whiskers/polylactic acid nanocomposites. Compos. Sci. Technol. 2006, 66, 2776-2784. [CrossRef]

45. Sapkota, J.; Kumar, S.; Weder, C.; Foster, E.J. Influence of Processing Conditions on Properties of Poly (Vinyl acetate)/Cellulose Nanocrystal Nanocomposites. Macromol. Mater. Eng. 2015, 300, 562-571. [CrossRef]

46. Roohani, M.; Habibi, Y.; Belgacem, N.M.; Ebrahim, G.; Karimi, A.N.; Dufresne, A. Cellulose whiskers reinforced polyvinyl alcohol copolymers nanocomposites. Eur. Polym. J. 2008, 44, 2489-2498. [CrossRef]

47. Li, C.; Sun, C.; Wang, C.; Tan, H.; Xie, Y.; Zhang, Y. Cellulose nanocrystal reinforced poly(lactic acid) nanocomposites prepared by a solution precipitation approach. Cellulose 2020, 27, 7489-7502. [CrossRef]

48. Sanders, J.E.; Han, Y.; Rushing, T.S.; Gardner, D.J. Electrospinning of Cellulose Nanocrystal-Filled Poly (Vinyl Alcohol) Solutions: Material Property Assessment. Nanomaterials 2019, 9, 805. [CrossRef]

49. Fabra, M.J.; López-Rubio, A.; Ambrosio-Martín, J.; Lagaron, J.M. Improving the barrier properties of thermoplastic corn starchbased films containing bacterial cellulose nanowhiskers by means of PHA electrospun coatings of interest in food packaging. Food Hydrocoll. 2016, 61, 261-268. [CrossRef] 
50. Martínez-Sanz, M.; Lopez-Rubio, A.; Villano, M.; Oliveira, C.S.S.; Majone, M.; Reis, M.; Lagarón, J.M. Production of bacterial nanobiocomposites of polyhydroxyalkanoates derived from waste and bacterial nanocellulose by the electrospinning enabling melt compounding method. J. Appl. Polym. Sci. 2016, 133. [CrossRef]

51. Martínez-Sanz, M.; Lopez-Rubio, A.; Lagaron, J.M. Dispersing Bacterial Cellulose Nanowhiskers in Polylactides via Electrohydrodynamic Processing. J. Polym. Environ. 2014, 22, 27-40. [CrossRef]

52. Martínez-Sanz, M.; Olsson, R.T.; Lopez-Rubio, A.; Lagaron, J.M. Development of bacterial cellulose nanowhiskers reinforced EVOH composites by electrospinning. J. Appl. Polym. Sci. 2012, 124, 1398-1408. [CrossRef]

53. Orr, M.P.; Shofner, M.L. Processing strategies for cellulose nanocrystal/polyethylene-co-vinyl alcohol composites. Polymer 2017, 126, 211-223. [CrossRef]

54. Mehrasa, M.; Asadollahi, M.A.; Nasri-Nasrabadi, B.; Ghaedi, K.; Salehi, H.; Dolatshahi-Pirouz, A.; Arpanaei, A. Incorporation of mesoporous silica nanoparticles into random electrospun PLGA and PLGA/gelatin nanofibrous scaffolds enhances mechanical and cell proliferation properties. Mater. Sci. Eng. C 2016, 66, 25-32. [CrossRef]

55. Zhang, D.; Karki, A.B.; Rutman, D.; Young, D.P.; Wang, A.; Cocke, D.; Ho, T.H.; Guo, Z. Electrospun polyacrylonitrile nanocomposite fibers reinforced with Fe3O4 nanoparticles: Fabrication and property analysis. Polymer 2009, 50, 4189-4198. [CrossRef]

56. Melendez-Rodriguez, B.; Castro-Mayorga, J.L.; Reis, M.A.M.; Sammon, C.; Cabedo, L.; Torres-Giner, S.; Lagaron, J.M. Preparation and Characterization of Electrospun Food Biopackaging Films of Poly(3-hydroxybutyrate-co-3-hydroxyvalerate) Derived From Fruit Pulp Biowaste. Front. Sustain. Food Syst. 2018, 2, 38. [CrossRef]

57. Melendez-Rodriguez, B.; Torres-Giner, S.; Lorini, L.; Valentino, F.; Sammon, C.; Cabedo, L.; Lagaron, J.M. Valorization of Municipal Biowaste into Electrospun Poly(3-hydroxybutyrate-co-3-hydroxyvalerate) Biopapers for Food Packaging Applications. ACS Appl. Bio Mater. 2020, 3, 6110-6123. [CrossRef]

58. Echegoyen, Y.; Fabra, M.J.; Castro-Mayorga, J.L.; Cherpinski, A.; Lagaron, J.M. High throughput electro-hydrodynamic processing in food encapsulation and food packaging applications: Viewpoint. Trends Food Sci. Technol. 2017, 60, 71-79. [CrossRef]

59. Figueroa-Lopez, K.J.; Cabedo, L.; Lagaron, J.M.; Torres-Giner, S. Development of Electrospun Poly(3-hydroxybutyrate-co-3hydroxyvalerate) Monolayers Containing Eugenol and Their Application in Multilayer Antimicrobial Food Packaging. Front. Nutr. 2020, 7, 140. [CrossRef]

60. Torres-Giner, S.; Pérez-Masiá, R.; Lagaron, J.M. A review on electrospun polymer nanostructures as advanced bioactive platforms. Polym. Eng. Sci. 2016, 56, 500-527. [CrossRef]

61. Redondo, A.; Jang, D.; Korley, L.T.J.; Gunkel, I.; Steiner, U. Electrospinning of Cellulose Nanocrystal-Reinforced Polyurethane Fibrous Mats. Polymers 2020, 12, 1021. [CrossRef]

62. Pirani, S.; Abushammala, H.M.N.; Hashaikeh, R. Preparation and characterization of electrospun PLA/nanocrystalline cellulosebased composites. J. Appl. Polym. Sci. 2013, 130, 3345-3354. [CrossRef]

63. Martínez-Sanz, M.; Olsson, R.T.; Lopez-Rubio, A.; Lagaron, J.M. Development of electrospun EVOH fibres reinforced with bacterial cellulose nanowhiskers. Part I: Characterization and method optimization. Cellulose 2011, 18, 335-347. [CrossRef]

64. Kenawy el, R.; Layman, J.M.; Watkins, J.R.; Bowlin, G.L.; Matthews, J.A.; Simpson, D.G.; Wnek, G.E. Electrospinning of poly(ethylene-co-vinyl alcohol) fibers. Biomaterials 2003, 24, 907-913. [CrossRef]

65. Yu, D.-G.; Xu, Y.; Li, Z.; Du, L.-P.; Zhao, B.-G.; Wang, X. Coaxial Electrospinning with Mixed Solvents: From Flat to Round Eudragit L100 Nanofibers for Better Colon-Targeted Sustained Drug Release Profiles. J. Nanomater. 2014, 2014, 967295. [CrossRef]

66. Shiku, Y.; Hamaguchi, P.Y.; Benjakul, S.; Visessanguan, W.; Tanaka, M. Effect of surimi quality on properties of edible films based on Alaska pollack. Food Chem. 2004, 86, 493-499. [CrossRef]

67. Kanatt, S.R.; Rao, M.S.; Chawla, S.P.; Sharma, A. Active chitosan-polyvinyl alcohol films with natural extracts. Food Hydrocoll. 2012, 29, 290-297. [CrossRef]

68. Arfat, Y.A.; Ahmed, J.; Hiremath, N.; Auras, R.; Joseph, A. Thermo-mechanical, rheological, structural and antimicrobial properties of bionanocomposite films based on fish skin gelatin and silver-copper nanoparticles. Food Hydrocoll. 2017, 62, 191-202. [CrossRef]

69. Agüero, A.; Morcillo, M.d.C.; Quiles-Carrillo, L.; Balart, R.; Boronat, T.; Lascano, D.; Torres-Giner, S.; Fenollar, O. Study of the Influence of the Reprocessing Cycles on the Final Properties of Polylactide Pieces Obtained by Injection Molding. Polymers 2019, 11, 1908. [CrossRef]

70. Faisant, J.B.; Aït-Kadi, A.; Bousmina, M.; Deschenes, L. Morphology, thermomechanical and barrier properties of polypropyleneethylene vinyl alcohol blends. Polymer 1998, 39, 533-545. [CrossRef]

71. Torres-Giner, S.; Echegoyen, Y.; Teruel-Juanes, R.; Badia, J.D.; Ribes-Greus, A.; Lagaron, J.M. Electrospun Poly(ethylene-co-vinyl alcohol)/Graphene Nanoplatelets Composites of Interest in Intelligent Food Packaging Applications. Nanomaterials 2018, 8, 745. [CrossRef]

72. Rojas-Lema, S.; Terol, J.; Fages, E.; Balart, R.; Quiles-Carrillo, L.; Prieto, C.; Torres-Giner, S. Microencapsulation of Copper(II) Sulfate in Ionically Cross-Linked Chitosan by Spray Drying for the Development of Irreversible Moisture Indicators in Paper Packaging. Polymers 2020, 12, 2039. [CrossRef]

73. Beck, S.; Bouchard, J.; Berry, R. Dispersibility in Water of Dried Nanocrystalline Cellulose. Biomacromolecules 2012, 13, 1486-1494. [CrossRef]

74. Di Giorgio, L.; Martín, L.; Salgado, P.R.; Mauri, A.N. Synthesis and conservation of cellulose nanocrystals. Carbohydr. Polym. 2020, 238, 116187. [CrossRef] 
75. Abdallah, W.; Kamal, M.R. Influence of process variables on physical characteristics of spray freeze dried cellulose nanocrystals. Cellulose 2018, 25, 5711-5730. [CrossRef]

76. Khoshkava, V.; Kamal, M.R. Effect of drying conditions on cellulose nanocrystal (CNC) agglomerate porosity and dispersibility in polymer nanocomposites. Powder Technol. 2014, 261, 288-298. [CrossRef]

77. Martínez-Sanz, M.; Lopez-Rubio, A.; Lagaron, J.M. Nanocomposites of ethylene vinyl alcohol copolymer with thermally resistant cellulose nanowhiskers by melt compounding (I): Morphology and thermal properties. J. Appl. Polym. Sci. 2013, 128, 2666-2678. [CrossRef]

78. Torres-Giner, S.; Gimenez, E.; Lagaron, J.M. Characterization of the morphology and thermal properties of Zein Prolamine nanostructures obtained by electrospinning. Food Hydrocoll. 2008, 22, 601-614. [CrossRef]

79. Peresin, M.S.; Habibi, Y.; Zoppe, J.O.; Pawlak, J.J.; Rojas, O.J. Nanofiber Composites of Polyvinyl Alcohol and Cellulose Nanocrystals: Manufacture and Characterization. Biomacromolecules 2010, 11, 674-681. [CrossRef]

80. Rojas, O.J.; Montero, G.A.; Habibi, Y. Electrospun nanocomposites from polystyrene loaded with cellulose nanowhiskers. J. Appl. Polym. Sci. 2009, 113, 927-935. [CrossRef]

81. Park, W.-I.; Kang, M.; Kim, H.-S.; Jin, H.-J. Electrospinning of Poly(ethylene oxide) with Bacterial Cellulose Whiskers. Macromol. Symp. 2007, 249-250, 289-294. [CrossRef]

82. Vannini, M.; Marchese, P.; Celli, A.; Lorenzetti, C. Strategy To Modify the Crystallization Behavior of EVOH32 through Interactions with Low-Molecular-Weight Molecules. Ind. Eng. Chem. Res. 2016, 55, 3517-3524. [CrossRef]

83. López-de-Dicastillo, C.; Gallur, M.; Catalá, R.; Gavara, R.; Hernandez-Muñoz, P. Immobilization of $\beta$-cyclodextrin in ethylenevinyl alcohol copolymer for active food packaging applications. J. Membr. Sci. 2010, 353, 184-191. [CrossRef]

84. Fernández, A.; Sánchez, M.D.; Ankerfors, M.; Lagaron, J.M. Effects of ionizing radiation in ethylene-vinyl alcohol copolymers and in composites containing microfibrillated cellulose. J. Appl. Polym. Sci. 2008, 109, 126-134. [CrossRef]

85. Lasagabaster, A.; Abad, M.J.; Barral, L.; Ares, A. FTIR study on the nature of water sorbed in polypropylene (PP)/ethylene alcohol vinyl (EVOH) films. Eur. Polym. J. 2006, 42, 3121-3132. [CrossRef]

86. Coleman, M.M.; Yang, X.; Zhang, H.; Painter, P.C. Ethylene-co-vinyl alcohol blends. J. Macromol. Sci. Part B 1993, 32, $295-326$. [CrossRef]

87. Cava, D.; Sammon, C.; Lagaron, J.M. Water diffusion and sorption-induced swelling as a function of temperature and ethylene content in ethylene-vinyl alcohol copolymers as determined by attenuated total reflection fourier transform infrared spectroscopy. Appl. Spectrosc. 2006, 60, 1392-1398. [CrossRef] [PubMed]

88. Nir, Y.; Narkis, M.; Siegmann, A. Morphology and infrared spectroscopy of strongly interacting polymer blends: EVOH/copolyamide-6/6.9. J. Macromol. Sci. Part B 1998, 37, 863-882. [CrossRef]

89. Lagaron, J.M.; Gimenez, E.; Catala, R.; Gavara, R. Mechanisms of Moisture Sorption in Barrier Polymers Used in Food Packaging: Amorphous Polyamide vs. High-Barrier Ethylene-Vinyl Alcohol Copolymer Studied by Vibrational Spectroscopy. Macromol. Chem. Phys. 2003, 204, 704-713. [CrossRef]

90. Mano, V.; Chimenti, S.; Ruggeri, G.; Pereira, F.V.; de Paula, E.L. P(CL-b-LLA) diblock copolymers grafting onto cellulosic nanocrystals. Polym. Bull. 2017, 74, 3673-3688. [CrossRef]

91. Cheng, D.; Wen, Y.; Wang, L.; An, X.; Zhu, X.; Ni, Y. Adsorption of polyethylene glycol (PEG) onto cellulose nano-crystals to improve its dispersity. Carbohydr. Polym. 2015, 123, 157-163. [CrossRef] [PubMed]

92. Kim, D.; Kwon, H.; Seo, J. EVOH nanocomposite films with enhanced barrier properties under high humidity conditions. Polym. Compos. 2014, 35, 644-654. [CrossRef]

93. Orr, M.P.; Sonekan, A.; Shofner, M.L. Effect of processing method on cellulose nanocrystal/polyethylene-co-vinyl alcohol composites. Polym. Eng. Sci. 2020, 60, 2979-2990. [CrossRef]

94. Noorani, S.; Simonsen, J.; Atre, S. Nano-enabled microtechnology: Polysulfone nanocomposites incorporating cellulose nanocrystals. Cellulose 2007, 14, 577-584. [CrossRef]

95. Singh, S.; Gaikwad, K.K.; Park, S.-I.; Lee, Y.S. Microwave-assisted step reduced extraction of seaweed (Gelidiella aceroso) cellulose nanocrystals. Int. J. Biol. Macromol. 2017, 99, 506-510. [CrossRef]

96. Zaman, M.; Xiao, H.; Chibante, F.; Ni, Y. Synthesis and characterization of cationically modified nanocrystalline cellulose. Carbohydr. Polym. 2012, 89, 163-170. [CrossRef]

97. Neto, W.P.F.; Silvério, H.A.; Dantas, N.O.; Pasquini, D. Extraction and characterization of cellulose nanocrystals from agroindustrial residue-Soy hulls. Ind. Crop. Prod. 2013, 42, 480-488. [CrossRef]

98. Yan, H.; Chen, X.; Feng, M.; Shi, Z.; Zhang, W.; Wang, Y.; Ke, C.; Lin, Q. Entrapment of bacterial cellulose nanocrystals stabilized Pickering emulsions droplets in alginate beads for hydrophobic drug delivery. Colloids Surf. B Biointerfaces 2019, 177, 112-120. [CrossRef]

99. Islam, M.S.; Karim, M.R. Fabrication and characterization of poly(vinyl alcohol)/alginate blend nanofibers by electrospinning method. Colloids Surf. A Physicochem. Eng. Asp. 2010, 366, 135-140. [CrossRef]

100. Cha, R.; He, Z.; Ni, Y. Preparation and characterization of thermal/pH-sensitive hydrogel from carboxylated nanocrystalline cellulose. Carbohydr. Polym. 2012, 88, 713-718. [CrossRef]

101. Sun, X.F.; Xu, F.; Sun, R.C.; Fowler, P.; Baird, M.S. Characteristics of degraded cellulose obtained from steam-exploded wheat straw. Carbohydr. Res. 2005, 340, 97-106. [CrossRef] 
102. Martínez-Sanz, M.; Lopez-Rubio, A.; Lagaron, J.M. Nanocomposites of ethylene vinyl alcohol copolymer with thermally resistant cellulose nanowhiskers by melt compounding (II): Water barrier and mechanical properties. J. Appl. Polym. Sci. 2013, 128, 2197-2207. [CrossRef]

103. Martínez-Sanz, M.; Lopez-Rubio, A.; Lagaron, J.M. Optimization of the Dispersion of Unmodified Bacterial Cellulose Nanowhiskers into Polylactide via Melt Compounding to Significantly Enhance Barrier and Mechanical Properties. Biomacromolecules 2012, 13, 3887-3899. [CrossRef]

104. Suryanegara, L.; Nakagaito, A.N.; Yano, H. The effect of crystallization of PLA on the thermal and mechanical properties of microfibrillated cellulose-reinforced PLA composites. Compos. Sci. Technol. 2009, 69, 1187-1192. [CrossRef]

105. Yu, H.; Yan, C.; Yao, J. Fully biodegradable food packaging materials based on functionalized cellulose nanocrystals/poly(3hydroxybutyrate-co-3-hydroxyvalerate) nanocomposites. RSC Adv. 2014, 4, 59792-59802. [CrossRef]

106. Yang, W.; Qi, G.; Kenny, J.M.; Puglia, D.; Ma, P. Effect of Cellulose Nanocrystals and Lignin Nanoparticles on Mechanical, Antioxidant and Water Vapour Barrier Properties of Glutaraldehyde Crosslinked PVA Films. Polymers 2020, 12, 1364. [CrossRef] [PubMed]

107. Ogunsona, E.O.; Mekonnen, T.H. Multilayer assemblies of cellulose nanocrystal-polyvinyl alcohol films featuring excellent physical integrity and multi-functional properties. J. Colloid Interface Sci. 2020, 580, 56-67. [CrossRef] [PubMed]

108. McCrum, N.G.; Buckley, C.P.; Bucknall, B. Principles of Polymer Engineering; Oxford University Press: Oxford, UK, 1988.

109. Razi, P.S.; Portier, R.; Raman, A. Studies on Polymer-Wood Interface Bonding: Effect of Coupling Agents and Surface Modification. J. Compos. Mater. 1999, 33, 1064-1079. [CrossRef]

110. Azizi Samir, M.A.S.; Alloin, F.; Dufresne, A. Review of Recent Research into Cellulosic Whiskers, Their Properties and Their Application in Nanocomposite Field. Biomacromolecules 2005, 6, 612-626. [CrossRef] [PubMed]

111. Zhang, Z.; Lim, L.-T.; Tung, M.A. Limonene transport and mechanical properties of EVOH and nylon 6,6 films as influenced by RH. J. Appl. Polym. Sci. 2001, 79, 1949-1957. [CrossRef]

112. Lagaron, J.M.; Catalá, R.; Gavara, R. Structural characteristics defining high barrier properties in polymeric materials. Mater. Sci. Technol. 2004, 20, 1-7. [CrossRef]

113. Maes, C.; Luyten, W.; Herremans, G.; Peeters, R.; Carleer, R.; Buntinx, M. Recent Updates on the Barrier Properties of Ethylene Vinyl Alcohol Copolymer (EVOH): A Review. Polym. Rev. 2018, 58, 209-246. [CrossRef]

114. Li, H.; Shi, H.; He, Y.; Fei, X.; Peng, L. Preparation and characterization of carboxymethyl cellulose-based composite films reinforced by cellulose nanocrystals derived from pea hull waste for food packaging applications. Int. J. Biol. Macromol. 2020, 164, 4104-4112. [CrossRef] [PubMed]

115. Karkhanis, S.S.; Stark, N.M.; Sabo, R.C.; Matuana, L.M. Water vapor and oxygen barrier properties of extrusion-blown poly(lactic acid)/cellulose nanocrystals nanocomposite films. Compos. Part A Appl. Sci. Manuf. 2018, 114, 204-211. [CrossRef]

116. Chowdhury, R.A.; Nuruddin, M.; Clarkson, C.; Montes, F.; Howarter, J.; Youngblood, J.P. Cellulose Nanocrystal (CNC) Coatings with Controlled Anisotropy as High-Performance Gas Barrier Films. ACS Appl. Mater. Interfaces 2019, 11, 1376-1383. [CrossRef]

117. Syverud, K.; Stenius, P. Strength and barrier properties of MFC films. Cellulose 2008, 16, 75. [CrossRef]

118. Nair, S.S.; Zhu, J.Y.; Deng, Y.; Ragauskas, A.J. High performance green barriers based on nanocellulose. Sustain. Chem. Process. 2014, 2, 23. [CrossRef]

119. Guinault, A.; Sollogoub, C.; Domenek, S.; Grandmontagne, A.; Ducruet, V. Influence of crystallinity on gas barrier and mechanical properties of pla food packaging films. Int. J. Mater. Form. 2010, 3, 603-606. [CrossRef]

120. Belbekhouche, S.; Bras, J.; Siqueira, G.; Chappey, C.; Lebrun, L.; Khelifi, B.; Marais, S.; Dufresne, A. Water sorption behavior and gas barrier properties of cellulose whiskers and microfibrils films. Carbohydr. Polym. 2011, 83, 1740-1748. [CrossRef]

121. Petersson, L.; Oksman, K. Biopolymer based nanocomposites: Comparing layered silicates and microcrystalline cellulose as nanoreinforcement. Compos. Sci. Technol. 2006, 66, 2187-2196. [CrossRef] 